\title{
Recent Advances in the Prediction of Weld Residual Stress and Distortion - Part 1
}

\section{A comprehensive review of the numerical modeling theory and methods for predicting weld residual stress and distortion}

\author{
BY Y. P. YANG
}

\begin{abstract}
Residual stresses and distortions are the result of complex interactions between welding heat input, the material's high-temperature response, and joint constraint conditions. Both weld residual stress and distortion can significantly impair the performance and reliability of welded structures. In the past two decades, there have been many significant and exciting developments in the prediction and mitigation of weld residual stress and distortion. This paper reviews the recent advances in the prediction of weld residual stress and distortion by focusing on the numerical modeling theory and methods. The prediction methods covered in this paper include a thermo-mechanical-metallurgical method, simplified analysis methods, friction stir welding modeling methods, buckling distortion prediction methods, a welding cloud computational method, integrated manufacturing process modeling, and integrated computational materials engineering (ICME) weld modeling. Remaining challenges and new developments are also discussed to guide future predictions of weld residual stress and distortion.
\end{abstract}

\section{KEYWORDS}

- Numerical Analysis • Residual Stess • Distortion

- Finite Element Analysis

\section{Introduction}

When steel structures are welded, distortion and welding residual stress could occur as a result of the localized high heat input and subsequent rapid cooling. Residual stress can influence welded structure performance in strength (Refs. 1, 2), fatigue (Ref. 3), and cracking during service (Refs. 4, 5). Distortion may also reduce the structure load capacity (Ref. 1). In addition to shrinkage and bending-type distortion modes, welds in thin-walled structures often produce residual stresses large enough to cause buckling, which can complicate distortion analysis and prediction (Ref. 6). The distortion makes the welded components difficult to fit to the downstreamed structures, which greatly increases the fitting cost. In addition, it is costly to reduce weld residual stress using postweld thermal (Refs. 7, 8) or mechanical (Ref. 9) procedures. It is also pricey to correct welding-induced distortion using the flame straightening process or mechanical method (Ref. 10). To better predict weld residual stress and distortion, significant progress has been achieved in the past two decades (Refs. 11, 12).

New methods of predicting weld residual stress and distortion and commercial software have been developed and matured for industrial uses (Refs. 13-20). Tremendous work has also been reported in using computational methods to predict and quantify the effect of the distortion and residual stress during the welding process. The most commonly used methods for predicting residual stress include empirical, semiempirical, and process simulation methods (Refs. 13-16). The most accurate process modeling method, a thermo-mechanical-metallurgical method (TMM) (Refs. 17, 18), was developed to simulate the entire physical process of welding, which includes metal deposition, melting/remelting, and microstructure evolution. Simplified methods (Refs. 19-21) such as inherent-strain a shrinkage force and lump-pass modeling methods were developed to provide a quick solution for predicting welding-induced distortions. Over the past two decades, there are many literature reviews (Refs. 13, 18-23) on the prediction of residual stress and distortion. But each review covers several specific areas and none is comprehensive. There is a need for a comprehensive review to summarize the recent advances in predicting and mitigating weld residual stress and distortion.

This paper reviews the recent advances in the prediction of weld residual stress and distortion. The review focuses on the numerical modeling theory and application in understanding and predicting weld residual stress and distortion. The review of prediction methods includes a thermo- 


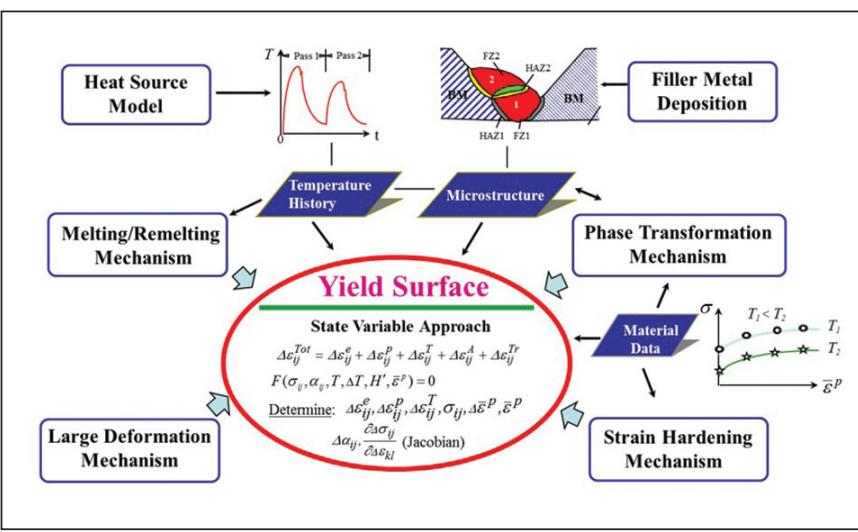

Fig. 1-A thermo-mechanical-metallurgical model for fusion welding.

mechanical-metallurgical method, simplified analysis methods, friction stir welding (FSW) modeling methods, buckling distortion prediction methods, a welding cloud computational method, integrated manufacturing process modeling, and integrated computational materials engineering (ICME) weld modeling. The components in the TMM method, which include heat source models, filler metal deposition, material melting, strain hardening, and phase transformation, were discussed. The inherent strain method is the most successful simplified analysis method, which is widely used for distortion prediction of large welded structures. Numerical methods to model FSW were reviewed for the prediction of weld residual stress and distortion. Three buckling distortion prediction methods were discussed, which include a thermal-elastic-plastic (TEP) method considering initial deformation, an inherent deformation method, and an eigenvalue method. New developments, including welding cloud computation, integrated manufacturing process modeling, and ICME modeling, were briefly discussed. Finally, remaining challenges and new development needs were discussed to guide future development in the field of weld residual stress and distortion.

\section{Prediction Methods}

Numerical modeling methods have been significantly developed in the past decade to predict temperature, weld residual stress, and distortion. Detailed analysis methods including a coupled TMM modeling method were developed to simulate the major physics involved in welding processes to better understand the evolution of microstructure, strain, stress, and distortion. Simplified analysis methods were developed to predict distortion on large welded structures. Analysis methods were also developed for solid-state welding processes such as resistance spot welding and FSW. An ICME framework was also proposed to integrate weld modeling technologies into structure design and performance prediction such as crash simulation and fatigue estimation. In addition, a cloud-based modeling method was developed to predict temperature, microstructure, weld residual stress, and distortion. The details are discussed in the following sections.

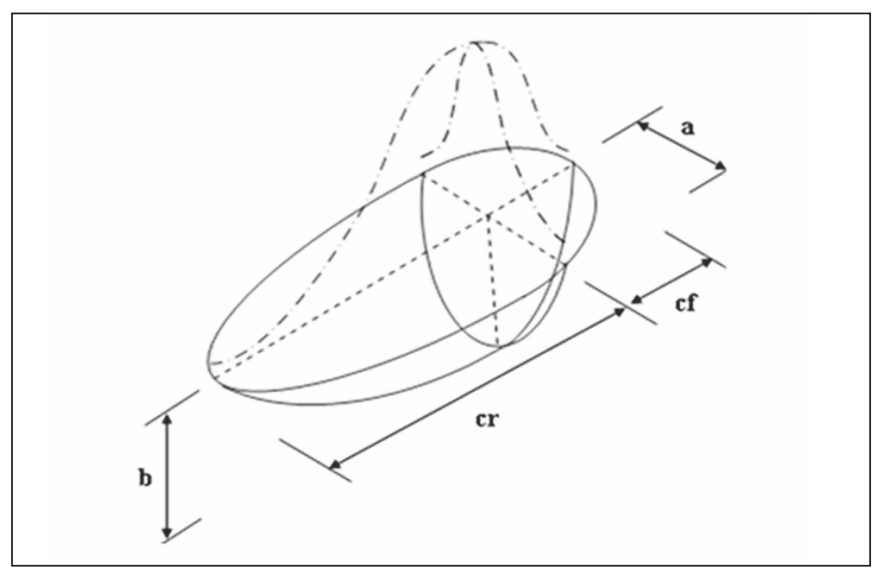

Fig. 2 - Parameters in Goldak's heat source model.

\section{Thermo-Mechanical-Metallurgical Method}

The thermo-mechanical-metallurgical method is the basic modeling method developed over the past few decades for computational welding mechanics methods (Ref. 24). The metallurgical part (material phase transformation modeling) in this method has been developed in recent years as highstrength steels are increasingly used. Many studies have been carried out using the thermo-elastic-plastic method while ignoring the metallurgical modeling either for simplicity or for unnecessarily including material modeling (Ref. 25). The thermo-elastic-plastic method, a sequentially coupled thermal and mechanical finite element (FE) simulation, has been applied to small welded joints such as butt joints (Ref. 26), fillet welds (Ref. 27), and fusion welding (Ref. 28) and to large welded structures (Refs. 29, 30). Numerical results from these studies showed reasonable agreement with the experimental measurements. However, it is important to model the major physical phenomena involved in the welding process, such as heat transfer, material melting/remelting, solidification, and phase transformation, to predict weld residual stress and distortion accurately (Ref. 31).

Figure 1 illustrates a TMM model for fusion welding (Ref. 32). A heat source model is selected based on the welding process to calculate the heat flux by inputting welding parameters. The calculated heat flux is passed to a heat transfer model to predict temperature history, which is then input into a microstructural model and a mechanical model. The microstructural model predicts microstructure phases resulting from the welding process, and the mechanical model predicts strain, stress, and distortion by simulating welding fixtures. Filler metal deposition, strain hardening, and large deformation should be considered in the mechanical model. Material melting and remelting during multipass welding should be modeled to predict weld residual stress and distortion correctly.

\section{Heat Source Models}

Heat source models are used in heat transfer analysis to predict temperature distributions and histories during the welding process. The intensity of the welding heat source can be described by either surface or volumetric distribution functions, which depend on welding processes. Gaussian distribu- 
tion was adapted as one of the surface distribution heat source models (Ref. 33). The surface heat-flux distribution in the $\mathrm{x}-\mathrm{z}$ plane of the moving arc is considered as a Gaussian distribution expressed by

$$
q_{s}=\frac{3 \eta Q}{\pi r^{2}} e^{\frac{x^{2}+(z+v t)^{2}}{-r^{2} / 3}}
$$

where $r$ is the effective radius of the heat source, $\eta$ is heat efficiency, $Q$ is the power, and $v$ is the traveling speed. This heat source model can also be used to calculate heat flux for autogenous gas tungsten arc welding (GTAW) (Ref. 33) and conduction-mode laser welding (Ref. 34).

Goldak's double-ellipsoidal model (Ref. 24), one of the volumetric distribution functions, is a nonaxisymmetric three-dimensional (3D) model that simulates a somewhat complex weld pool. This model is widely used for simulating fusion welding processes including GTAW, gas metal arc welding (GMAW), submerged arc welding (SAW), and flux cored arc welding (FCAW) (Refs. 33, 34). In this model, heat flux at a point and a time is calculated as

$$
\begin{aligned}
& q(x, y, z, t)=f \frac{6 \sqrt{3} Q \eta}{a b c \pi \sqrt{\pi}} e^{\frac{-3 x^{2}}{a^{2}}} e^{\frac{-3 y^{2}}{b^{2}}} e^{\frac{-3[z+v t]^{2}}{c^{2}}} \\
& Q=I U
\end{aligned}
$$

where $x, y$, and $z$ are the local coordinates; $a, b, c$ are the semi-axes of the ellipsoid (as shown in Fig. 2); $f$ is a factor; $\eta$ is heat efficiency; $Q$ is the power; and $v$ is the traveling speed. For the front quadrant, $f$ is equal to $f_{f}$ and $c$ is equal to $c_{f}$, and for the rear quadrant, $f$ is equal to $f_{r}$ and $c$ is equal to $c_{r}$. The fractions satisfy the condition that $f_{f}+f_{r}=2$. The approximated arc efficiency used in the model is 0.85 for GMAW, 0.65 for GTAW and FCAW, and 0.95 for SAW. Welding parameters and weld bead profiles can be inputted into to this model to calculate heat flux for heat transfer analysis to predict temperature history.

Another volumetric model for the deep penetration of the heat source is a conical model used for electron beam and laser beam welding, as presented in Fig. 3. The power density of this model is described with a Gaussian distribution on the truncated plane (e.g., $x-z)$ as seen in Ref. 35,

$$
q=q_{\max } \exp \left(-\frac{3\left[x^{2}+(z-v t)^{2}\right]}{r_{c}^{2}}\right)
$$

Where $q_{\max }$ is the maximum heat flux. $r_{c}$ is a characteristic radius at the current position y and linearly decreases from the top surface at $y_{t}$ to the bottom $y_{b}$.

$$
r_{c}=r_{t}-\frac{\left(r_{t}-r_{b}\right)\left(y_{t}-y\right)}{y_{t}-y_{b}}
$$

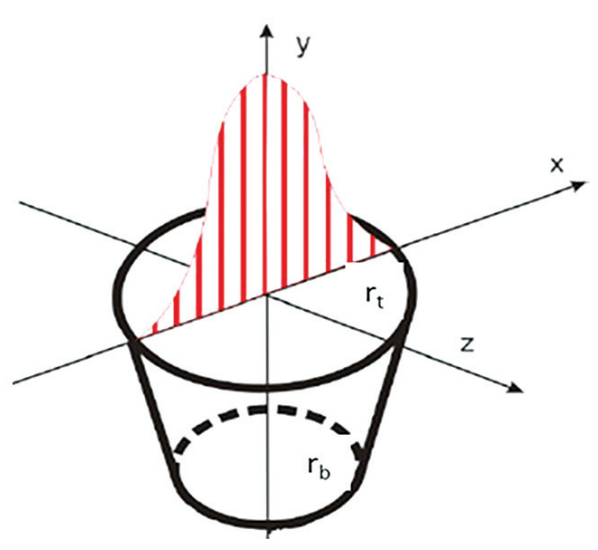

Fig. 3 - Parameters in the conical heat source model.

Where $r_{t}$ and $r_{c}$ are the corresponding characteristic radii at the top and bottom.

For the hybrid laser arc welding (HLAW) process, a combination of the Goldak and conical heat source models can be used to predict the heat flux with the Goldak heat source model used to simulate arc welding and the conical heat source model to simulate laser welding (Refs. 36, 37). For a HLAW butt joint, a width ratio is defined to describe the geometrical characteristics of the "wine-glass" weld profile. The energy ratio between the arc and laser is introduced as a parameter for the formation of the weld profile, the generation of welding deformation, and residual stress. Ma et al. (Ref. 38) determined the correlation between the energy ratio and width ratio of a weld profile through experimentation and 3D thermal elastic-plastic analysis.

The surface and volumetric heat source models have been implemented to commercial codes (using ANSYS, ABAQUS, MARC, and SYSWELD softwares) for thermal analysis of welding processes (Ref. 39). For example, Goldak's heat source model was implemented with a FORTRAN subroutine DFLUX in ABAQUS to simulate a moving welding torch and calculate heat flux in thermal analysis to predict temperatures (Ref. 39).

Before starting the modeling process, an experiment must be conducted to measure the geometrical parameters of heat source models. A weld macrograph has to be prepared by cutting weld samples to obtain weld width and penetration. We also need to know the weld pool dimension from the top view. It can be done by real-time measurement (Refs. 40,41 ) or by stopping the welding torch after welding reaches the steadystate condition. From a total weld pool dimension, it will be difficult to determine the front and rear length of the doubleellipsoidal model. A sensitivity analysis can be conducted to determine the ratio of front and rear length. It was found that the ratio has a significant effect on distortion and residual stress prediction (Refs. 42, 43).

However, the surface and volumetric heat source models as shown in Equations 1-4 may not meet the needs for modeling some specific applications. Therefore, new heat source models were developed for these applications. A new heat source model (cylindrical) was established to match the actual weld profile, which was implemented in commercial code MARC with a FORTRAN subroutine. Four bead geometry parameters (penetration depth, bead width, waist width, 


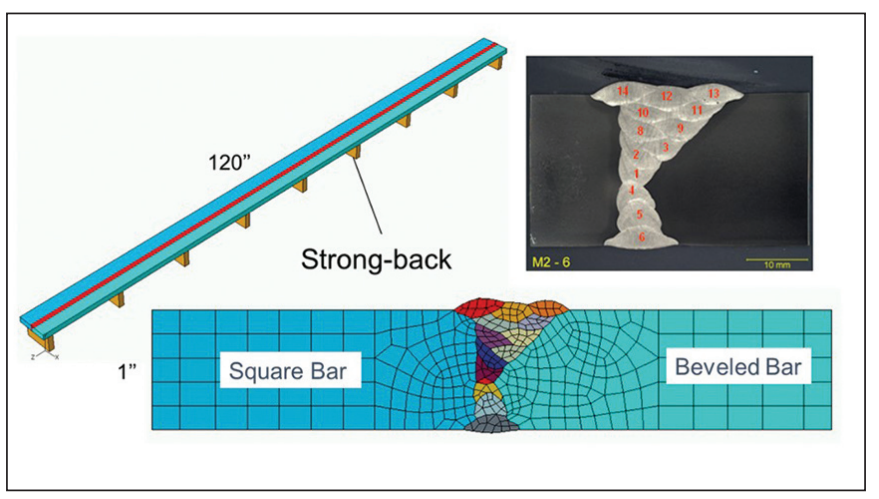

Fig. 4-A finite element weld mesh for multipass welding.

and depth of the waist) were used to compare between the experimental and simulation results. The results showed that the cylindrical heat source model can match the actual shape of the fiber laser welding feasibly (Ref. 44). An eggconfiguration volumetric heat source model with a lower number of parameters was proposed for nonsymmetric heat energy distribution. This model conserves the continuity in profile during a moving heat source problem (Ref. 45). Yue et al. (Ref. 46) proposed an equivalent heat source model based on the Gaussian heat source model, with consideration to the groove angle effect on the heat source. The temperature field distribution was simulated through the COMSOL multiphysics field software. The experimental results confirmed the validity of the proposed model.

\section{CFD Model}

The surface and volumetric heat source models are limited in simulating weld pool fluid flow. Therefore, some weld bead shapes are difficult to predict, such as the crater-finger in shielded arc welds (Ref. 47). In addition, experiments must be conducted to determine the geometrical parameters of a heat source model. Arrizubieta et al. (Ref. 48) found that the heat conduction simulation significantly overestimated the transient temperature distribution and resulted in a less accurate prediction of molten pool geometry compared to the heat transfer and fluid flow simulation. Therefore, computational fluid dynamics (CFD) approaches were taken to predict weld bead geometry (Ref. 49) for the GTAW process. The impinging effect of molten droplets on the molten pool was investigated by Cao et al. (Ref. 50) in GMAW. Bag et al. (Ref. 51) proposed to determine the volumetric geometrical parameters for SAW.

Podder et al. (Ref. 52) found that in SAW, the increased heat flow caused by turbulence of the molten metal due to various driving forces such as buoyancy, plus Lorentz and Marangoni, formed a complicated bead shape. This may be simulated by artificially increasing the thermal conductivity of the weld metal in a heat transfer analysis without including CFD. A higher value of thermal conductivity provided a better correlation with the experimentally measured shapes of the weld pool. The regression equations developed in Podder's work can be used to determine the double-ellipsoidal heat source parameters, along with the increased thermal conductivity of the molten weld metal, to provide a realistic picture of heat flow for SAW of plates with thicknesses ranging from 6 to $16 \mathrm{~mm}$.

A combined framework of CFD and FE analysis was established by Choen et al. (Ref. 53) for metallurgical analysis of a gas metal arc weld. Turner et al. (Ref. 54) incorporated a CFD model in FE analysis to predict the weld pool shape and then conducted thermo-mechanical analysis to predict residual stress and distortions. Anthony et al. (Ref. 55) developed a desktop computer model to simulate arc plasma, filler wire transfer, and weld pool dynamics in a lap-fillet weld geometry. The predictions of the model showed good agreement with measurements of weld geometry and weld composition. Weld residual stress and distortion were also predicted using this model.

Ideally, this integrated CFD and FE analysis model should be used to predict residual stress and distortion. But there are very few applications due to the complexity of the numerical model and computational cost. It is anticipated that this integrated model will be used in the future to predict residual stress and distortion.

\section{Filler Metal Deposition}

Welding can be performed with or without filler material depending on which process is used and the requirement of the weld geometry. Filler metal is gradually deposited onto a weld joint during welding. In FE mesh generation, all weld passes are built with fine elements based on their final weld bead shape (Ref. 56), as shown in Fig. 4. Two techniques and their combination have been developed to model the filler metal deposition.

The first technique is the element birth and death technique (Refs. 57-59). In the beginning of the analysis, all weld elements are removed. During analysis, each weld pass is added to the model based on welding sequence. This technique works well for small deformation analysis. For large deformation analysis, the removed weld elements will not follow the movement of their surrounding nodes. This can result in a severely distorted, or even collapsed, element.

Lindgren and Hedblom (Ref. 60) developed a technique to control the volume of the activated elements, which also optimized the position of the nodes for minimized element distortion and correct geometrical shape of each weld pass. Peric et al. conducted a sequential thermo-mechanical FE analysis of T-joint fillet welding (Refs. 61, 62) and butt joint welding (Ref. 63). In the thermal analysis, the element birth and death technique was applied to simulate a weld filler deposition, while a mechanical analysis was performed without using the element birth and death technique to avoid possible problems due to large displacements induced by large strains. The simulated results demonstrated that the proposed method can be effectively used to predict the residual stresses and distortions. Biswas et al. (Ref. 59) developed a finite element model (FEM) of single-pass, singlesided submerged arc welding of square butt joints based on the commercial code. The effect of filler metal deposition was taken into account by implementing the element birth and death technique.

The second technique is the "quiet elements" technique (Ref. 64) in which all FE for weld passes are kept in the model during analysis, but their stiffness and thermal conductivity are very low so that the quiet elements have a minimal 
effect on the analysis. The quite elements become active and assign their normal material properties when the weld pass is deposited. However, decreasing the stiffness of the quiet elements too much will give an ill condition stiffness matrix with numerical problems as a result. Yang et al. (Ref. 65) used this quiet element technique to simulate the laser cladding manufacturing process for aero engine repair.

A combination of the two techniques has been developed for a large structure with long welds. In the beginning of the analysis, all weld passes are removed from the model. During the analysis, each weld pass is added to the model based on welding sequence. The added weld pass is assigned very low stiffness and thermal conductivity, initially. Then the elements for this pass are activated by giving correct material properties based on the welding torch location. This combined technique has been used to simulate the welding of aircraft tie-downs to the ship deck with a multipass FCAW process (Ref. 66), and it also simulated a laser additive manufacturing process to predict microstructure, residual stress, and deformation (Ref. 67) in commercial code ABAQUS with a user-developed subroutine USDFLD.

\section{Material Data}

Temperature-dependent thermal-physical and mechanical properties are critical for predicting temperature, residual stress, and distortion for a welding process. To conduct precise numerical simulations of the welding process, flow stress curves from room temperature up to the melting point are required (Ref. 68). Transient temperature distribution in a welded joint is highly affected by thermal conductivity (Ref. 69). Numerical sensitivity results show that yield stress and Young's Modulus have significant and small effects, respectively, on the residual stress and distortion (Ref. 70). To improve the calculation speed, a constant density, thermal conductivity, and specific heat at about $600^{\circ} \mathrm{C}$ for steel can be given in thermal analysis instead of temperature-dependent thermal properties. The prediction temperature distributions and magnitudes will be similar to the ones with temperature-dependent thermal properties.

For common materials, temperature-dependent thermalphysical and mechanical properties can be found in handbooks. If they are not available, high-temperature tests have to be conducted to measure the material properties for welding simulation. However, if material properties are not available in public literature and testing is also not an option, JMatPro software can be used to obtain the thermo-mechanical material properties. Schwenk et al. (Ref. 71) gave an overview about the experimental determination and analysis of the material properties needed as input data for a welding simulation. The temperature-dependent thermal-physical and thermo-mechanical material properties for dual-phase steel, austenitic steel, and precipitation-hardenable aluminum alloy were given in a ready-to-use format for a numerical welding simulation. Kaars et al. (Ref. 72) determined the material data of 22MnB5 for welding simulation by testing and literature review. Bhatti et al. (Ref. 73) found that density can be taken as constants in thermal analysis. For residual stress prediction, yield strength is the most important material property, and for distortion prediction, yield strength and thermal expansion should be temperature dependent.

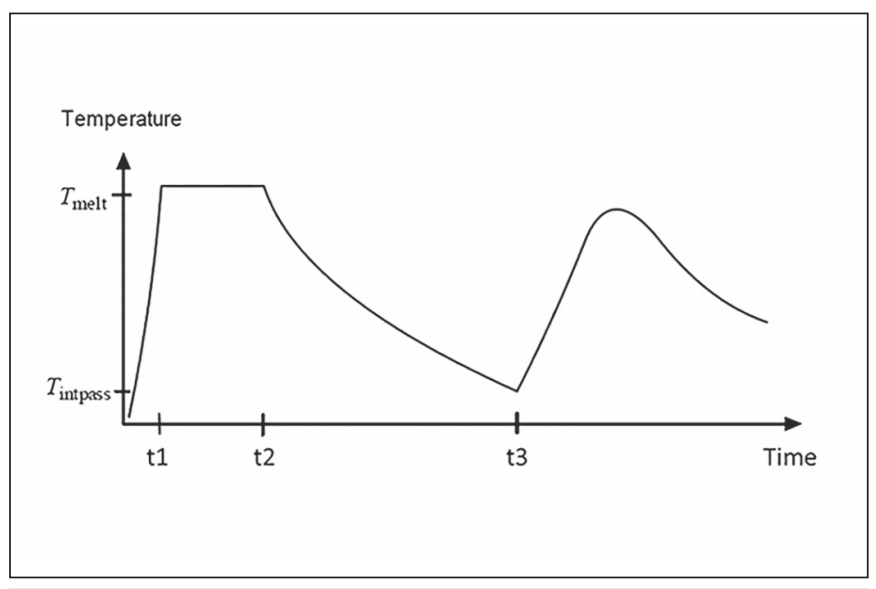

Fig. 5 - Temperature history in a newly deposited weld pass.

Recently, ICME-based tools and techniques were identified as the best path forward for distortion mitigation through computational simulation of the welding process. Significant efforts were investigated to measure the required temperature-dependent material properties to achieve accurate computational results for distortion and residual stress. Noteworthy properties include specific heat, thermal conductivity, coefficient of thermal expansion, elastic modulus, yield strength, and flow stress of alloys, from room temperature up to near melting point. In addition, the temperatures associated with on-heating and on-cooling phase transformations and their variation with heating rate, cooling rate, and peak temperature are also important for the prediction of stress and distortion evolution. The testing included some of the most common marine steels used in the construction of U.S. Naval vessels; namely, DH36, HSLA-65, HSLA-80, HSLA-100, HY-80, and HY-100. Bechetti et al. (Ref. 74) issued the first report for DH36 material data. This report is part of a seven-part series detailing the pedigreed steel data. The first six reports discuss the material properties for each of the individual steel grades, whereas the final report will compare and contrast the measured steel properties across all six steels, while also comparing them to the available literature data.

\section{Material Melting Modeling}

Most commercial FE software was developed based on solid mechanics theory and cannot model material melting. When a material is melted, strain and stress go to zero. During solidification, material strength is recovered. Tensile strain shows behind the weld pool, which induces hot cracking for certain materials such as 2024 high-strength aluminum. However, commercial FE software predicted a large compressive strain in the weld pool and behind the weld pool. Therefore, weld hot cracking cannot be modeled.

Yang et al. (Ref. 75) provided a numerical method by involving an annealing temperature to model material melting, which has been implemented in ABAQUS/UMAT subroutine. ABAQUS took this concept by introducing an annealing temperature in the material data input. But ABAQUS only eliminated the effective plastic strain, not all strain and stress components. Although it is not a full solu- 


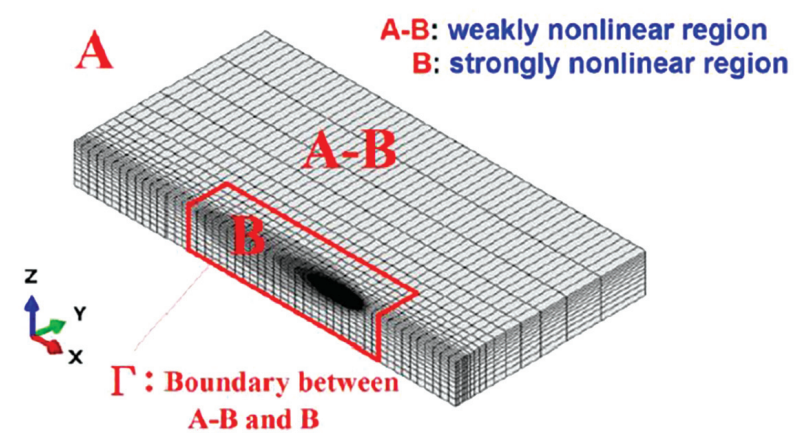

Fig. 6-Concept of iterative substructure method (ISM).

tion for modeling material melting, it is sufficient to predict distortion in a welding simulation.

Huang et al. (Ref. 76) performed a transient thermomechanical simulation to predict residual stress on stainless plates welded using the laser welding process. The effect of strain hardening, annealing, and melting on the residual stress prediction was clarified through a parametric study. It was shown that these heat effects must be taken into account for accurate prediction of residual stresses in laser welded stainless sheets. Reasonable agreement was obtained among residual stresses predicted by the numerical method and measured by both x-ray diffraction and the contour method.

\section{Strain Hardening Modeling}

A strain hardening mechanism models the yield strength increases as a result of repeated heating and cooling thermal cycles in multipass welding. There are three types of material hardening mechanisms: isotropic, kinematic, and combined isotropic-kinematic hardening. Mullins and Gunnars (Ref. 77) modeled a multipass pipe welding of 316 stainless steel and determined that the isotropic hardening model gave the best overall agreement with experimental measurements. The combined hardening model gave good agreement for predictions of the hoop stress but tended to underestimate the magnitude of the axial stress. The kinematic hardening model consistently underestimated the magnitude of both the axial and hoop stress. Xiong et al. (Ref. 78) conducted FE simulations on thick-walled, girth-welded austenitic steel pipes fabricated from Esshete 1250 austenitic steel. The simulations considered both simple isotropic and kinematic hardening behavior, and a large matrix of the Lemaitre-Chaboche mixed isotropic-kinematic hardening material constitutive models, with a focus on examining the most accurate evolutionary hardening behavior for weld metal. The predicted residual stresses were validated using incremental deep hole drilling techniques and the contour method. The mixed isotropic-kinematic hardening model predicted more accurate residual stresses than the simple isotropic and kinematic hardening models. In general, isotropic hardening could be selected for single-pass welding. For multipass welding, weld residual stress could be over predicted with isotropic hardening. A general rule is to use kinematic hardening or combined isotropic-kinematic hardening when the number of weld passes is more than three.

\section{Phase Transformation Modeling}

When medium carbon steel or alloy steel with sufficient carbon equivalent are joined by the fusion welding process, solid-state phase transformation has significant influences on the formation of welding residual stress. To predict welding residual stress in such steels using the numerical simulation method, the coupling of thermo-metallurgical-mechanical behaviors should be carefully considered. It has been recognized that three factors related to solid-state phase transformation potentially affect the formation of welding residual stress. These three factors are volume change caused by austenite-martensite (bainite) transformation, mechanical property variation due to microstructure change, and transformation-induced plasticity (Refs. 79, 80).

Deng et al. (Ref. 81) investigated the effects of volume change, yield strength variation, and transformationinduced plasticity (TRIP) on the generation of residual stresses in P92 steel welded joints experimentally and numerically. The simulation results showed that the volume change and the yield stress variation have a great effect on the magnitude and distribution profiles of residual stresses in the fusion zone and heat-affected zone (HAZ) and even alter the sign of the stresses, while TRIP has a relaxation effect on the tendency of stress variation during phase transformation. Yaghi et al. (Ref. 82) and Deng et al. (Ref. 83) conducted FE analysis to predict residual stresses generated in the weld region and HAZ of a butt-joint welded P91 steel pipe. Solid-state phase transformation (SSPT), which is characteristic of P91 steel during welding thermal cycles, was modelled in the FE analysis by allowing for volumetric changes in steel and associated changes in yield stress due to austenitic and martensitic transformations. The results indicate the importance of including SSPT in the simulation of residual stresses during the welding of P91 steel. Xu et al. (Ref. 84) investigated the effects of SSPT on the repair welding residual stress distribution of multilayer and multipass welding in P91 steel. The results show that transverse compressive stress and a low longitudinal stress area are generated in the final pass due to martensite transformation. Compared with different zones along the thickness direction, the effect of SSPT is greater around the outer surface than around the internal fusion zone.

Chen et al. (Ref. 85) developed a TMM model in which user-defined subroutines in ABAQUS model SSPT kinetics and transformation-induced plasticity on a SA508 steel multipass 


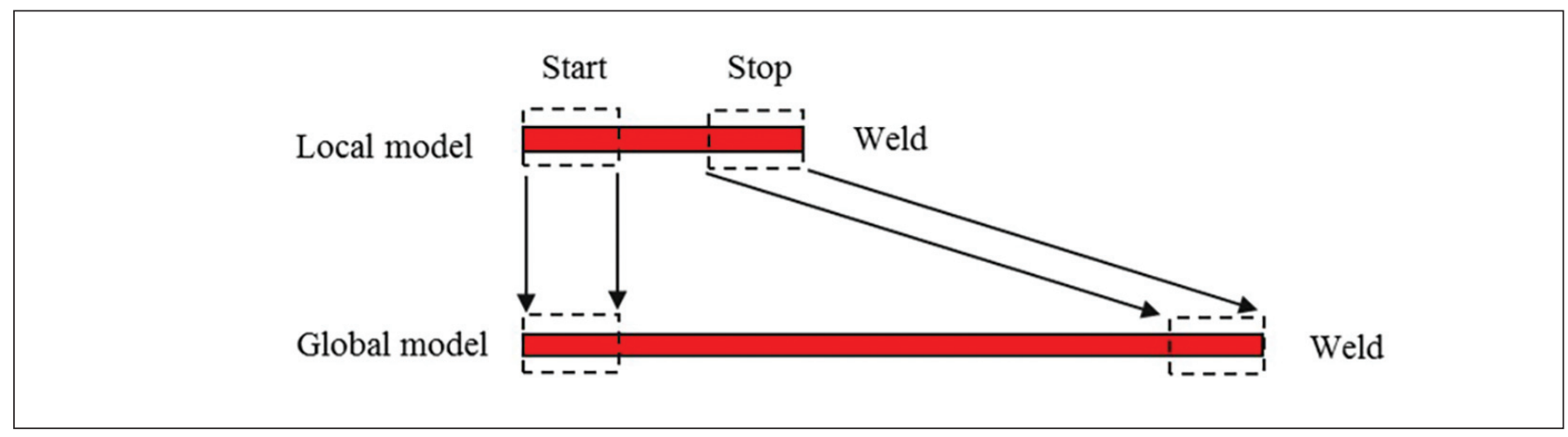

Fig. 7-A stretch mapping method.

joint. Numerical simulations illustrated how the transformation and heat transfer/cumulative behavior associated with different welding process conditions resulted in the generation of triaxial compressive and tensile stresses in the upper and underlying weld beads at the multipass welded joint, respectively. Moreover, an additional simulation model with SSPT but without TRIP was developed to reveal the potential effects of TRIP on weld residual stress distribution. Xia et al. (Ref. 86) implemented the Koistinen-Marburger model and Leblond phase evaluation model in a user subroutine to simulate the continuous heating and cooling transformation. The thermal cycle and cooling rate were taken into account to predict the metallurgical transformation behavior and phase fraction.

In theory, the thermal-mechanical-metallurgical model should be a coupled model since interactions may exist between the thermal, mechanical, and metallurgical model. However, the metallurgical model is often ignored while predicting weld residual stress and distortion for low carbon steels because martensite could not be produced in the welded joint (Ref. 87). For high-strength steels such as HY-80 and HY-100, the metallurgical model has to be included because the martensite microstructure phase will be formed in the welded joint. Phase-transformation-induced plasticity must be included to predict weld residual stress and distortion. Deng's simulation results revealed that the final residual stress and the welding distortion in low carbon steel do not seem to be influenced by the solid-state phase transformation (Ref. 88). However, for the medium-carbon steel, the final residual stresses and the welding distortion seem to be significantly affected by the martensitic transformation (Refs. 88, 89).

\section{Large Deformation Mechanism}

A TMM FE analysis could be conducted with both small and large deformation. For small deformation analysis, numerical calculations are performed on the original coordinates, while for large deformation analysis, numerical calculations are performed on the deformed coordinates. For a 3D solid model, predicted residual stress and distortion could be similar. However, for a shell element of thin-welded structures, large deformation (non-linear geometry) must be specified. Otherwise, the predicted distortion could be much smaller than the experimental measurement. For a buckling distortion, the predicted deformation shape might not be correct (Ref. 90).

\section{Model Application Examples}

3D TMM FEM has been well recognized as an accurate method, since it can deal with the complicated temperature and stress problems. The thermo-mechanical-metallurgical model or the thermo-mechanical model have been applied to help solve numerous industrial problems. For example, Brust et al. (Ref. 91) conducted FE analyses to simulate the buttering and welding process of carbon steel pipe welded to stainless steel pipe using alloy 82/182 filler wire to identify the root reason of the primary water stress corrosion cracking detected in several U.S. nuclear plants. Yang et al. (Ref. 92) developed a TMM model to understand the mechanical and metallurgical reasons for the ductility-dip cracking and solidification cracking in a down-comer steel pipe and proposed a solution to mitigate the cracking. Hashemzadeh et al. (Ref. 93) investigated the residual stresses in steel plates induced by multipass welding numerically and experimentally. The element birth and death technique was used to simulate the welding process in ANSYS. An experimental study was performed to calibrate the numerical results for both thermal and mechanical analyses. The x-ray diffraction method was used to measure the residual stress. A good agreement was achieved between numerical and experimental results.

\section{Simplified and Fast Analysis Methods}

For the accurate prediction of residual stresses and deformations, the numerical simulations of the welding process should be carried out using a nonlinear TMM method and 3D solid finite elements. Because of its highly nonlinear and transient behavior, the thermo-mechanical welding analysis requires considerable computer power, especially in the case of models with a large number of finite elements. It makes such simulations impractical or even impossible. Therefore, the TMM method employing a full 3D FE mesh is limited to small or medium structures.

Predicting welding-induced residual stress and distortion in large and complex structures is a computationally intensive task. Although computational speed has been increased using graphical processing units, parallel computation with multiprocessors in desktop workstations, and supercomputers (Refs. 94-96), it still could take days and weeks to analyze a large welded structure to predict distortion using a transient moving-arc TMM analysis method for one welding sequence. 
This makes it impractical to perform welding sequence optimization, which may require simulations of a hundred test welding sequences, using full thermo-elastic-plastic analyses. To solve this problem, simplified analysis methods were developed for fast distortion prediction.

\section{D Modeling Method}

There exist a number of methods for decreasing the computational time, or actually the wall-clock time of the simulation. The most obvious and straightforward is to reduce the geometrical dimension (e.g., from a 3D solid model to a two-dimensional [2D] plane strain model). In a 2D model, the heat transfer in the welding direction (perpendicular to the 2D plane) is ignored and the welded geometry is greatly simplified. Therefore, a 2D model is very limited at predicting welding-induced distortion. But 2D models have been widely used to predict weld residual stress such as in a pipe girth weld. It is anticipated that the application of 2D models for welding simulation will be diminished as computer speed become faster and faster.

Generally, the 2D weld residual stress modeling method can be classified into two categories. The first category is to apply a uniform heat flux (Ref. 91) or a temperature (Ref. 97) on a weld pass. The second category is to apply nonuniform heat flux using a heat source model (Ref. 98).

Figure 5 illustrates the applying temperature method, which represents a typical temperature history in a weld pass during welding. The temperature is rapidly rising to the melting temperature, held for a period of time, and then cools down naturally. The temperature will rise because of the following weld pass. Zang et al. (Ref. 99) applied this modeling method to predict weld residual stress with an axisymmetric model in a thin-walled pipe that was welded with six passes. The modeling method captures the main characteristics of the through-thickness stress distributions by validation against experimental measurements.

Boring et al. (Ref. 98) applied a nonuniform heat flux method to develop a temper bead welding procedure for an amine tower repair. The 2D axisymmetric model was used to simulate the shielded metal arc welding temper bead weld procedure. Thermomechanical analyses were conducted to determine the residual stress distributions on the inner surface of the amine tower. Goldak's double-ellipsoidal model, as shown in Equation 2, was used to simulate the heating process. The $\mathrm{z}$ direction in the model was the welding direction and $\mathrm{z}$ varied from $-c_{r}$ to $c_{f}$ where $c_{r}$ was the rear quadrant and $c_{f}$ was the front quadrant as shown in Fig. 2. This analysis method allows using a 3D model to simulate the process of a welding torch moving through a 2D plane.

\section{Lumping (Grouping) Weld Passes}

Multipass welding is often used to weld a thick structure with a butt joint configuration. Sometimes, 50 or more weld passes are used to fill a V or U group. Residual stress analyses of multipass welding requires a lot of time and computer memory. The grouping weld pass method has been used to reduce the computational time. For example, Brust et al. (Ref. 91) grouped three physical weld passes into one numerical pass, which greatly reduced the computational time.
With the lump pass analysis method, Zhu et al. (Ref. 100) lumped five weld passes into two weld passes, which reduced the total number of weld passes from 40 to 16 so that the analysis time was greatly reduced.

A study has been conducted to investigate the effect of grouping weld passes on residual stress prediction in multipass thick butt joint welding (Ref. 101). The residual stress prediction by thermo-elastic-plastic FE analysis was verified by neutron diffraction measurement. It was found that if the number of grouped welding passes is less than half of the physical welding passes, predicted residual stresses have a large difference with measured ones. Therefore, the grouping weld passes can be done to an extent and without affecting the model prediction accuracy.

\section{Combined Solid and Shell Elements}

Combining solid and shell elements is a good technique to reduce computational time for weld simulation, especially for thin-walled structures. The 3D solid elements are used only in the weld and its vicinity, where the thermal gradients are high, while in the rest of the model, shell elements are used. Accordingly, this shell/3D technique combines the accuracy of the full 3D model and computational efficiency of a shell FE solution, reducing the model size and computation cost. Moreover, it is important to model the connection between solid and shell elements correctly since a solid element and a shell element have a different degree of freedom.

The temperature, residual stress, and distortion on a Tjoint were studied with a solid model and a combined solid and shell element model. The same distortion trends and magnitudes were predicted with both models. Therefore, a combined 3D solid and shell model can be considered as an effective method to estimate the distortion of a large structure (Refs. 102, 103). Analysis suggested that the size of the 3D zone in the combined solid and shell model should be approximately three-wall thicknesses of the thicker plate. The combined solid and shell model was also validated on a large panel structure with experimental data. It was shown that the simulated results obtained by the solid/shell modeling technique were in good agreement with the results observed experimentally (Ref. 104). Chen et al. (Ref. 105) investigated the residual stresses and postweld deformations on a large panel structure using a mixture of shell elements with section integration and solid 3D finite elements to speed-up the calculation process. The whole model was essentially created with shell elements while only the weld bead was created with solid ones.

The combined solid and shell model is highly applicable in a practical engineering analysis since the panel structures are generally composed of stiffeners with attached plates of different thicknesses. It is shown that the main advantage of the model is that it provides a significant reduction in the computational time needed for the simulation of the welding process and thus enables efficient nonlinear transient analyses on large structures. The advantages of using the combined solid and shell model can be better seen in cases of numerical simulations of extremely large structures, where it is possible to create much larger areas with shell elements than in the analyzed case, so that the percentage savings on time can be significantly higher. 


\section{Adaptive/Dual Mesh Technique}

Adaptive mesh refinement is a method of adapting the accuracy of a solution within certain high temperature or high stress regions of simulation, dynamically and during the time the solution is being calculated. Runnemalm and Hyun (Ref. 106) presented an adaptive mesh scheme for both transient thermal analysis and stress analysis. Huang et al. (Ref. 76) developed an adaptive mesh method to simulate the laser welding of stainless steel plates to predict residual stress and distortion. Hamide et al. (Ref. 107) developed an adaptive mesh technique for thermalmetallurgical numerical simulation of GTAW. The refinement employs an anisotropic mesh pattern with a combined thermal-metallurgical criterion. The adaptive refinement method is useful for efficient thermal analysis, but it cannot be easily implemented in commercial software for extended application. In addition, data transfer between the thermal analysis and subsequent stress analysis is inevitable, because a mesh pattern adequate for stress analysis is much different from that in thermal analysis.

To keep the same mesh in thermal and mechanical analyses, Huang et al. (Ref. 108) proposed a dual mesh scheme based on the feature of localized strong heat transfer in welding that significantly cuts down the computation time. Both a fine and a coarse mesh are utilized to analyze the same welding process. In the fine mesh model, the elements and nodes within a local region around the weld pool are activated and those outside of this region are not necessarily computed. The local region is updated in accordance with the movement of the welding heat source. The solution of the region outside the local region can be obtained by computing on the coarse mesh. Linear interpolation is then employed to transfer the temperature results from coarse mesh to fine mesh. Under this computation framework, the accelerated mechanical analysis schemes can directly use the temperature data for fast computation. The numerical results on a bead-on-plate model show good agreement with conventional fine mesh analysis and experimental measurement.

\section{Iterative Substructure Method}

A transient thermo-elastic-plastic analysis may take several hours or weeks due to the high nonlinearity of the transient welding phenomena. In standard FEM, the repeated convergence computation is performed for the whole model. The iteration numbers for all elements are the same regardless if the convergence speed is fast or slow, which leads to time-consuming computation. To reduce the computing time, Murakawa et al. (Ref. 109) proposed an iterative substructure method (ISM) for small deformation welding problems. Huang et al. (Ref. 110) extended ISM to large deformation welding problems such as those found in thinplate welding.

The basic concept of ISM is that the regions in the whole FE model with different levels of nonlinearity are divided and solved iteratively until the residuals on the interfaces of these regions converge to a small value. As shown in Fig. 6, $\mathrm{FE}$ analysis with ISM was performed in the regions A-B and $B$. The $B$ region was defined by elements with a high transient temperature. Newton's method was employed in this region to achieve a fast convergence. The boundary between the $\mathrm{B}$ region and the remaining region $\mathrm{A}-\mathrm{B}$ was fixed for each degree of freedom. Since the $B$ region is very small, it was possible to find a solution within a short time. After the solution was obtained, analysis on the full model A was carried out using the solution as the initial condition.

A FEM analysis code for the multipass welding was developed based on the iterative substructure method, which was applied to simulate the dissimilar metal welds in pressurized water reactor piping systems. The analysis provided accurate results in a high-speed computation (Ref. 111). Huang et al. (Ref. 76) applied ISM combined with the adaptive mesh method to simulate the laser welding of stainless plates. Xray diffraction (XRD) and the contour method were used to measure the surficial and internal residual stress, respectively. Reasonable agreement was obtained among residual stresses by the numerical method, XRD, and the contour method. Buckling distortion mode and magnitude agreed well between experiment and simulation. The analysis speed was 50 times faster than a commercial code.

Taking a similar approach as ISM, a sub-structuring technique was proposed for a welding simulation with commercial codes (Ref. 112). The analyzed model was divided into two parts: the linear region and the nonlinear region. The elastic isotropic material model was assigned to the linear region with elastic behavior during the welding process. The elastic-plastic material model, assuming isotropic hardening, was applied to the nonlinear region, which was close to the heat source. The predicted residual stresses were validated experimentally on several different small scale specimens with XRD techniques. The developed simulation method was successfully demonstrated on complex welded structures in a construction equipment vehicle.

\section{Instantaneous TEP Methods}

Instantaneous thermal-elastic-plastic (TEP) analysis methods such as the lump-pass analysis procedure (Ref. 113) and the instantaneous heat source model (Ref. 114) were developed for fast analysis. The lump-pass procedure was implemented in ABAQUS while the instantaneous heat source model was used in MARC for welding simulation. These two methods are very similar in that a weld pass or a segment of weld pass is heated up in a short time without simulating the heat torch moving. This approach effectively reduces the calculation time by eliminating the effect of a moving arc, but it still requires iterations to achieve equilibrium because of material nonlinearity and plastic deformation. The accuracy of the predicted distortion is not as good as transient moving-arc thermo-elastic-plastic analysis because it is difficult to determine a heat input. But it is a good method to predict distortion in a structure with shortlength welds (Ref. 56).

\section{Prescribed Temperature Approach}

The prescribed temperature was developed to shorten computational time during a thermo-elastic-plastic analysis. A temperature field is directly applied to the subsequent analyses as an external load. The prescribed temperature method needs a thermal analysis beforehand. A recent func- 
tional extension for the process simulation in commercial software ABAQUS has been devoted to create such a temperature field (Ref. 115). Zhu et al. (Ref. 100) combined the lumping weld pass technique and prescribed temperature approach to predict residual stress in box structures. Thermal analysis was conducted to predict temperature history using Goldak's double-ellipsoidal model for physical weld passes. Then the temperature histories were averaged and applied on numerical lumped passes.

A traveling temperature function method (Refs. 116, 117) was developed to improve the instantaneous thermal-elasticplastic analysis method. At first, a quasi-steady state welding temperature field was achieved with the transient moving-arc solution. Then a coordinate and time-dependent temperature function was developed based on the temperature field. With this function, the nodal temperatures in a large model were calculated and stored as a function of time. The temperature history was input into a mechanical model to predict weld distortion. Several structures including cylindrical and conical structures and a high-speed train roof were modeled and compared with a transient moving-arc thermo-elastic-plastic analysis and experiment. The comparison between the two analyses showed a good agreement.

The error between computed results from the two modeling methods and the experimental results was no more than $10 \%$. This analysis method improved the accuracy of instantaneous thermal-elastic-plastic analysis methods, but the computational time was still long.

\section{Inherent Strain Method}

The elastic FE simulation with inherent strain or the inherent deformation method is the most successful method for predicting welding distortion in large and complex welded structures. The inherent strain method was proposed by Ueda (Ref. 21) to measure residual stress initially and then has been widely used to predict welding deformation (Refs. 118-121). This section introduces the theory, the validation, and the applications of this method based on published literature.

\section{Concept and Theory}

According to the theory of thermo-mechanical-metallurgical analysis, the total strain $\left(\varepsilon^{\text {Total }}\right)$ could be expressed as:

$$
\varepsilon^{\text {Total }}=\varepsilon^{e}+\varepsilon^{T}+\varepsilon^{p}+\varepsilon^{c}+\varepsilon^{P h}
$$

where $\varepsilon^{e}$ is elastic strain, $\varepsilon^{T}$ is thermal strain, $\varepsilon^{p}$ is plastic strain, $\varepsilon^{c}$ is creep strain, and $\varepsilon^{P h}$ is phase transformation induced strain. Inherent strain $\varepsilon^{*}$ is expressed in Equation 6 , which is the source of welding deformation and residual stress.

$$
\varepsilon^{*}=\varepsilon^{T}+\varepsilon^{p}+\varepsilon^{c}+\varepsilon^{P h}
$$

In all components of inherent strain, the creep strain is too small and often ignored. Thermal strain will disappear after the welding temperature cools down. Phase-transformation-induced strain becomes a part of plastic strain in the final structure. Therefore, the plastic strain is the domain component (Ref. 122). It can be obtained by experiment or a thermo-mechanical-metallurgical analysis.

Lu et al. (Ref. 123) employed the TEP analysis to predict strains on a two-pass butt joint of aluminum alloy welded by GMAW. Based on the inherent strain theory, the transverse and longitudinal inherent strain of the joints were decomposed from the total strains and applied to both a solid and a shell model to calculate residual stress. The results from the solid and shell models using both TEP and ISM were consistent, which indicates that the inherent strain method is an efficient and accurate analysis method.

\section{Obtain Inherent Strain}

Although the inherent strain method has been demonstrated to be accurate, convenient, and cost effective in the prediction of weld residual stresses and distortion, how to obtain inherent strain for distortion prediction remains to be an issue since inherent strain depends on the thermal characteristics of the welding process and the geometric details of the joint and structure, as well as the fixture constraints. Deng et al. (Refs. $124,125)$ proposed to employ the thermal-elastic-plastic FE method to estimate inherent deformations for different typical welding joints on smaller-scale welded structures. However, a small welded structure may not represent the structure stiffness from a large welded structure. Duan et al. (Ref. 126) developed a concept of a "rigid border" boundary condition in which a rigid part was added to the frontier of the small-scale model to keep the boundary in plane. In order to represent the mechanical conditions imposed by the rest of the structure, the rigidity of the rigid part may be changed by adjusting the value of Young's modulus. Deng et al. (Ref. 104) proposed to use the combined 3D solid/shell modeling technique to account for the structure stiffness from large-scale structures.

\section{Apply Inherent Strain}

Inherent strain is full-field information and varies in the welds and structure. Even in a weld, inherent strain is different in the start, middle, and end regions. How to apply inherent strain obtained from a small-scale model to a largescale model remains a challenging issue. The inherent deformation method, average plastic strain method, and equivalent load method were all developed to apply the inherent strain method to predict distortion.

Inherent deformation. Because it is difficult to apply inherent strain on a FEM, it is possible to assume that there is an inherent amount of deformation (inherent deformation) for each section perpendicular to the welded line. Inherent deformation in the longitudinal (x) and the transverse (y) direction can be calculated with the following equations (Ref. 127):

$$
\delta_{x}^{*}=\frac{1}{h} \iint \varepsilon_{x}^{*} d y d z
$$

$$
\delta_{y}^{*}=\frac{1}{h} \iint \varepsilon_{y}^{*} d y d z
$$




$$
\begin{aligned}
& \theta_{x}^{*}=\frac{12}{h^{3}} \iint\left(z-\frac{h}{2}\right) \varepsilon_{x}^{*} d y d z \\
& \theta_{y}^{*}=\frac{12}{h^{3}} \iint\left(z-\frac{h}{2}\right) \varepsilon_{y}^{*} d y d z
\end{aligned}
$$

where $\delta_{x}^{*}$ and $\delta_{y}^{*}$ are the inherent displacements in the longitudinal and the transverse directions, and $\theta_{x}^{*}$ and $\theta^{*}$ are the inherent bending in the longitudinal and the transverse directions.

Wang et al. (Ref. 127) investigated the inherent deformations of thin plate bead-on-plate welding with varying plate thicknesses for eight different materials. First, the 3D thermal-elastic-plastic FEM based on the interactive substructure method was used to compute welding deformations. A database of inherent deformations for eight different materials, including 144 computational cases, was developed. The relationship between the welding heat input parameter and inherent deformations was established. Wang et al. (Ref. 128) applied the inherent deformation method to predict distortion on a spherical structure which consisted of 14 thin bent plates and two circular polar plates. The inherent deformation was determined from a thermo-mechanical analysis with 3D solid elements on a butt joint. Tian et al. (Refs. 129, 130) developed an intelligent model based on a support vector machine, back propagation neural network, and genetic algorithm to predict the inherent deformations of a fillet-welded joint. The training samples were obtained from numerical experiments conducted by the thermalelastic-plastic FE analysis. In this model, the welding speed, current, voltage, and plate thickness were considered as input parameters, and the longitudinal and transverse inherent deformations were corresponding outputs.

Average plastic strain. Fusion welding being a quasistatic process, the distribution of average plastic strains caused by welding might be assumed to remain constant along the entire length of welding. The total plastic strains of all the elements in the welding zone of width $\left(w_{p}\right)$ is obtained by integration of them over this zone. Hence, the average plastic strain is obtained by dividing the width of the welding zone as shown in the following equation:

$$
\hat{\varepsilon}_{x, y}^{p}=\frac{1}{w_{p}} \int_{0}^{w_{p}} \varepsilon_{x, y}^{p}(y) d y
$$

where $\varepsilon^{\wedge p}{ }_{x, y}$ is the average $\mathrm{x}$ and $\mathrm{y}$ components of plastic strains. Biswas et al. (Ref. 131) applied the average plastic strain method to predict distortion using an elastic analysis on a large stiffened plate panel. Analysis results showed that the average plastic strain method has a better accuracy than the inherent strain method.

Equivalent load. Khurram et al. (Ref. 132) investigated an efficient FE technique based on inherent-strain-named equivalent load to predict welding deformations and residual stresses in butt joints. The equivalent load was calculated by integration of inherent strain, which is a function of the highest temperature and degree of restrain. To get more accurate results for distortion prediction, an effort was made to improve the equivalent load method (Ref. 133). The separate average loads were applied at the start, middle, and end regions of the welding line instead of the same average load throughout the weld length. This proposed method was validated with experimentally obtained results, which showed a perfect agreement and hence, confirmed its efficacy.

Barsoum et al. (Ref. 134) compared the inherent strain, inherent deformation, and equivalent load methods to predict weld distortion of T-type fillet welds. They concluded that the inherent strain method was better than the other two methods for angular distortion estimation and inherent deformation and equivalent load methods are more suitable for estimating longitudinal and transverse shrinkage.

The ISM was used as one of the most efficient analysis methods to predict welding deformation. However, some research results (Refs. 135, 136) indicated that it generally overestimates the magnitude of distortion by about $7-10 \%$. The errors were mainly induced by the methods of obtaining and applying inherent strain. The error can be minimized by improving the methods to obtain and apply inherent strain.

\section{Application Examples}

The ISM has been widely used to predict welding-induced distortion in small and large structures with an elastic analysis. If the analysis is conducted with an elastic-plastic analysis, this method can be used to predict weld residual stress in large structures. Murakawa et al. (Ref. 137) and Li et al. (Ref. 138) employed the ISM and introduced an interface element to investigate the influence of the initial gap between the plates on the plate deflections on a large panel structure sample. Wang et al. (Ref. 139) applied the ISM method to predict the out-the-plane welding deformations in a large welded panel of a car carrier ship.

\section{Local-to-Global Method}

A local-to-global method (Refs. 140, 141) was developed by further refining the ISM and making the inherent method more robotic for weld distortion prediction. This method includes two FE models: local models and a global model. The local models are analyzed to predict plastic strains with a transient moving-arc thermal-elastic-plastic analysis and the global model is analyzed with an elastic or elastic-plastic method to predict distortion by mapping the predicted plastic strains.

Several local-to-global strain mapping methods including direct mapping, symmetric mapping, rotation mapping, and stretch mapping were developed in a quick distortion prediction tool (EWI Q-Weld) (Ref. 142). The stretch-mapping method is a powerful method for mapping strain from a local model to a global model, as shown in Fig. 7. The weld start portion and stop portion are directly mapped to the global model. The middle length of the local model is stretched to match the global length. This mapping method was developed because the weld start and stop portion have different plastic strains than the middle part.

The local model is a part of the modeled structure which needs a fine finite-element mesh. The simulated weld length in the local model depends on material properties, welding process, and welding parameters. It can be determined by 


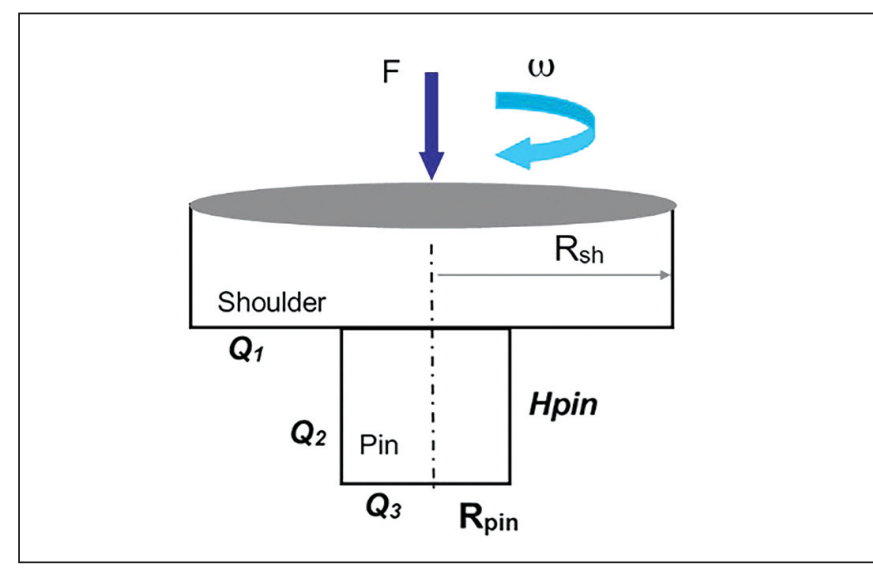

Fig. 8 - An idealized friction stir welding tool.

conducting several numerical analyses with different lengths. The minimum length to achieve a steady-state condition is the simulated weld length in the local model. For steel welded with GMAW, the local-model length is $300 \mathrm{~mm}$ long. The boundary condition of the local model should be close to the constraint conditions during welding of global welded structures (Ref. 143). The global model is built by meshing the entire modeled structure. The mesh in the global model can be different than the local model. To reduce the computational time, the global model uses a coarse mesh because plastic strains are similar along the weld except at the weld start and stop location (Ref. 144).

To help identify local models from a welded structure, a far- and close-weld theory was developed by numerical experimentation. A critical distance was determined below, which weld interactions have to be modeled during predicting plastic strains. The weld interactions were modeled by analyzing all possible welding sequences in the local models, and the welding-sequence-dependent plastic strains were saved to a database. For each welding sequence produced by an optimization code, Q-Weld will search the database to find the corresponding plastic strains to predict distortion, which will be compared with an objective function to determine the optimal welding sequence (Ref. 144).

Zhu et al. (Ref. 145) compared the thermo-elastic-plastic method, the local-to-global method, and the substructuring method to predict weld distortion and residual stress on a fillet weld and a multipass butt joint. It was concluded that the local-to-global method is very time efficient and the estimated longitudinal residual stresses show a good agreement with the experimental measurements.

\section{Friction Stir Welding Modeling Methods}

The FSW process involves physical couplings between mechanics and heat transfer, very large deformations, and strain rates in the stirring zone around the pin. Numerical simulation of the FSW processes enables estimation of different process parameters such as tool geometry and speeds. Simulation is not an easy task, however, since it involves the interaction of thermal and mechanical phenomena. Some established numerical modeling techniques have been developed that can explain and predict important features of the process physics involved in FSW (Ref. 146). The FSW models cover a broad range of complexity, from the simple conduction heat transfer models (Ref. 147), to the metal flow models (Ref. 149), to the fully-coupled models (Refs. 150, 151) in which the viscoplastic flow and the heat transfer are modeled for predicting temperature and residual stress distributions. Below, two practical methods are discussed to predict FSW-induced residual stress and distortion in which metal flow is ignored.

\section{Transient Thermal-Elastic-Plastic Analysis}

A physical-based, coupled, thermo-mechanical model was developed and used to investigate thermo-mechanical behavior during FSW. Heat generated from friction and plasticity was modeled using a heat source model. Figure 8 shows a FSW tool in which the pin has a cylindrical shape. During welding, the shoulder and pin will make contact with the weldment. Heat will be generated by friction on the contact surfaces. The total heat $\left(Q_{t}\right)$ including friction-induced heat from all three surfaces and heat generation from plastic energy dissipation can be expressed as (Ref. 152):

$$
Q_{t}=\frac{2}{3} \pi \tau \omega\left(R_{s h}^{3}+R_{p i n}^{2} H_{p i n}\right)+\tau \varepsilon^{p l}
$$

where $\mathcal{E}^{p l}$ is plastic strain increment.

The surface heat flux calculated in Equation 13 is applied on the shoulder surface and the body flux calculated with Equation 14 is applied in the pin volume. Note that heat generation from plasticity is not explicitly included in Equations 13 and 14. Its effect is considered in determining the heating efficiency $(\eta)$.

$$
\begin{gathered}
q_{s}(r, T)=\frac{3}{2 \pi} 0.75 \eta Q_{t} \frac{r}{R_{\text {sh }}^{3}-R_{\text {pin }}^{3}} \\
q_{b}(r, T)=\frac{0.25 \eta Q_{t}}{\pi R_{\text {pin }}^{2} H_{\text {pin }}}
\end{gathered}
$$

The above discussed heat source model has been widely used to predict weld residual stress and distortion. Compared to fusion welding, residual stresses in FSW joints are expected to be low due to a relatively low heat input. However, apart from the heat input, the force from the tool also plays an important role in the development of welding stresses. Analysis results and experimental measurement showed that due to the effect of the tool force, the longitudinal residual tensile stresses became smaller and were asymmetrically distributed at different sides of the weld center. The peak of the tensile residual stresses at the retreating side was lower than that at the advancing side (Ref. 153). The down force applied on the FSW tool significantly reduces residual stress. This is because the down force forges and extrudes the materials around the tool to reduce the residual strain in the weld, which leads to the reduction of residual stress. Furthermore, the mechanical loads change the correlation of strain on the top and bottom surfaces of the sheet, which results in a change of the distortion pattern (Ref. 154). 
Khosa et al. (Ref. 155) investigated the thermomechanical behavior during the FSW of AA6082-T6 using the thermo-mechanical model. To cope with the high calculation time and distortion of the mesh, built-in features of the code, mass scaling, the arbitrary Lagrangian-Eulerian (ALE) method, and mesh remapping were used. With the help of this model, the effects of process parameters on the temperature displacement behavior of the workpiece were studied. Yan et al. (Ref. 156) conducted thermo-elasticplastic analysis to predict distortion on a FS-welded panel, including four $\mathrm{T}$ stiffeners. Nie et al. (Ref. 157) studied the effects of process parameters on temperature and residual stress in FSW. Costa et al. (Ref. 158) conducted an experiment and a fully coupled thermo-mechanical FE analysis to study the distortion and residual stresses in FSW of thin AA5754-H22 aluminum plates. The numerical results also indicated using ultra-high welding speeds enabled suppressed distortion in thin plates welding.

\section{Inherent-Strain-Based Analysis Method}

The out-of-plane distortion of large thin-walled structures induced by FSW was predicted with the inherentstrain-based analysis method. Yu et al. (Ref. 159) developed a local-to-global method in which the nonuniform stress distribution along the weld was accurately computed with a small structure. By using an interpolation function, the stress components in the start, middle, and end regions of the weld in the small structure were mapped to the corresponding locations in the large thin-walled structure to predict out-of-plane distortion. Jang et al. (Ref. 160) suggested an equivalent load method based on the inherent strain approach as an efficient welding deformation and residual stress analysis method for large scale FSW structures of aluminum alloy Al6061-T6 sheet metal. The results showed fairly good agreement with those of existing FE analyses as well as the FSW experiments.

Dialami et al. (Ref. 161) proposed a local-global strategy for the computation of residual stresses in FSW. A coupling strategy between the analysis of the process zone near the pin tool (local level analysis) and the simulation carried out for the entire structure to be welded (global level analysis) was implemented to accurately predict the temperature histories and, thereby, the residual stresses in FSW. The ALE formulation was adopted to deal with the rotation of complex pin shapes. The output of this local analysis was the heat generated either by plastic dissipation or by friction, and it was used as the power input for the welding analysis at the structural (global) level. The outcomes of this analysis are the distortions and the residual stresses.

\section{Buckling Distortion Prediction}

Thin-gauge materials are increasingly used in today's high-performance welded structures in automotive, aircraft, shipbuilding, and other industries. It is well known that buckling distortions have been a major concern in welding fabrication of such structures. Unlike the stable type of welding-induced distortions, which can be adequately captured by performing a thermo-plastic simulation of actual welding procedures, buckling distortions in welded struc- tures are of an unstable type and require the use of appropriate buckling analysis procedures incorporating the welding-induced residual stress state.

Including initial conditions. One unique part of buckling distortion is that initial weld residual stress and imperfection affect the final predicted distortion. Without considering the plate's initial conditions, the predicted distortion could be opposite to the experimental measurement. A FEM procedure able to predict buckling distortion by incorporating weld residual stress and initial deformation was developed (Ref. 162). With this modeling method, the underlying mechanisms associated with welding-induced buckling distortions were studied, and the optimized welding procedures were developed (Ref. 90).

Inherent deformation analysis method. In a thermalelastic-plastic FE analysis of welding-induced buckling in a large thin-plate welded structure such as a ship panel, it would be extremely difficult to converge computation and obtain the results when both nonlinear material and geometry are modeled. Based on the inherent deformation method, Deng et al. (Ref. 163) and Wang et al. (Refs. 164, 165) developed an elastic FE analysis method with a shellelement model to predict welding-induced buckling distortion in production ship panels.

Eigenvalue analysis. Buckling distortion was assessed with a history-independent buckling modeling method (Ref. 166), as shown in the equation:

$$
\lambda_{i}\left([K]_{R S}+[K]_{T T T}\right)\{u\}_{i}=\{0\}
$$

where $[K]_{R S}$ represents weld residual stress, $[K]_{T T T}$ the stress induced by transient thermal tensioning (TTT), $u$ displacement, and $\lambda$ eigenvalue. For welding without applying TTT, $[K]_{T T T}$ will be zero. By solving this elastic buckling problem, the eigenvalue can be obtained for each buckling mode. The minimum eigenvalue is the most likely buckling mode. If the eigenvalue is smaller than one, buckling will happen in the structure. This means that weld residual stress exceeds the critical buckling load and leads to structure buckling. Wang et al. (Ref. 167) investigated welding-induced buckling of thin-plate welded structures using the eigenvalue analysis and elastic FE analysis based on the inherent deformation theory. Bead-on-plate welding was examined. Measured outof-plane welding distortion indicated that saddle-type buckling was produced after cooling. Eigenvalue analysis showed the computed lowest buckling mode was the saddle type and the corresponding critical force was less than the applied tendon force (longitudinal inherent shrinkage). It was also concluded that the tendon force was the dominant reason for buckling and determined the buckling mode, and initial deflection and inherent bending were considered to be disturbances which trigger buckling.

\section{Welding Cloud Computation}

Weld modeling technology tools are typically accessible only to engineers and designers with a background in $\mathrm{FE}$ analysis who work with large manufacturers, research institutes, and universities with access to high-performance computing (HPC) resources. Small and medium enterprises (SMEs) in the United States do not typically have the human 


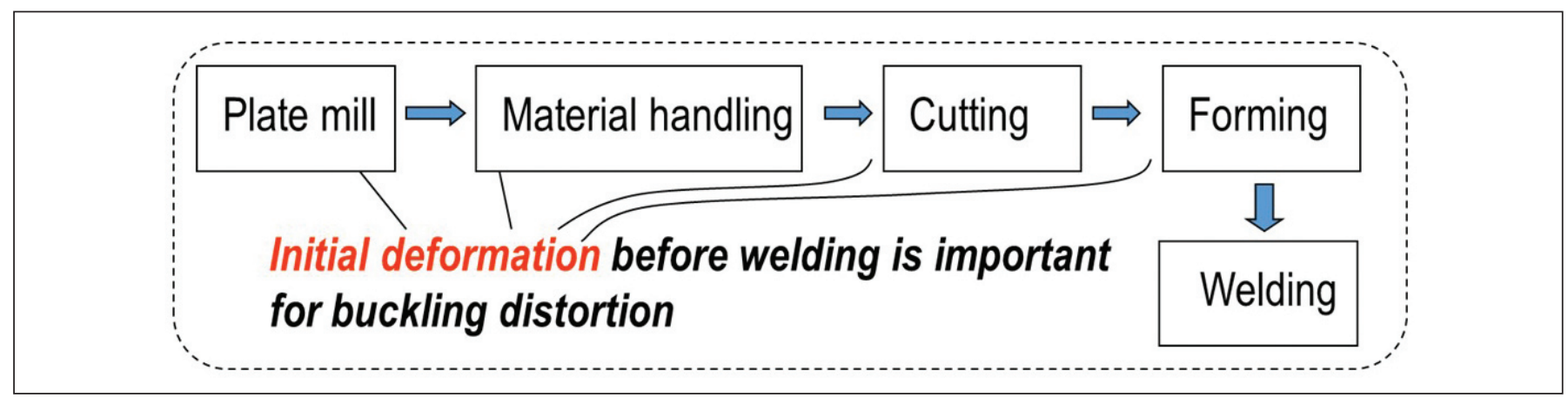

Fig. 9-A typical manufacturing process flow in production.

and computational resources needed to adopt and utilize weld modeling technology.

To close this gap and address the need of SMEs to gain access to this important design tool, a 2D online weld application software tool (EWI WeldPredictor [Ref. 168]) was developed by EWI and Ohio Supercomputer Center (OSC) from 2007 to 2009 (Refs. 169, 170). This tool allows engineers with no background in FE to access HPC resources and apply weld modeling technology to optimize their welding process and improve the design of their welded structures. More than 800 worldwide users tested this application. Although WeldPredictor was a huge advancement and enabler, the application could not address the majority of real-world design problems because of the following major drawbacks:

- The application uses a 2D model, which results in many limitations.

- Only arc welding processes are modeled by the software tool.

- The application was built on the ABAQUS commercial software platform, which requires expensive software licenses.

To address these issues, a new online welding software modeling tool for digital manufacturing using the cloud for HPC was developed by EWI, Parallel Works, and OSC (Ref. 171) and was funded by the Digital Manufacturing and Design Innovation Institute. This tool uses 3D FE models and includes the most common types of welding processes: arc, laser, and hybrid laser arc welding. Standard weld joints (butt, T-, and lap joints) were included in the software tool. Open source FE codes - SALOME, CalculiX, Paraview were used as a solver to replace ABAQUS. However, this cloud-based welding simulation tool was not able to launch due to the project shutting down.

\section{Integrated Manufacturing Process Modeling}

The prediction of the final shape of a component is of great interest to the manufacturing industry. The level of demand may increase due to multistage processes. Therefore, including all steps of the manufacturing chain (see Fig. 9) in predicting weld residual stress and distortion is key to being successful. However, more complex manufacturing procedures that include assembling of formed parts with forgings and castings via welding have been modelled with simplifications, resulting in reduced prediction accuracy.

Schill and Odenberger (Ref. 172) investigated the possibility of combining different process simulations in the manufacturing chain of an aerospace component made of
Alloy 718. The major objective of this study was to develop methods for performing coupled simulations using different FE codes rather than to evaluate the prediction accuracy. Steffenburg-Nordenström and Larsson (Ref. 173) considered a manufacturing chain including forming, welding, and heat treatment of a V-shaped leading edge of a vane manufactured from Alloy 718. They concluded that the history of the material after forming had a considerable effect on the amount of residual stresses in the subsequent steps of the manufacturing process chain. Huang et al. (Ref. 174) reported similar results in Q235 steel, concluding that the initial distortions from forming can largely influence the buckling distortion during welding. Bauer et al. (Ref. 175) investigated a forming and welding process chain of a DC04 tube. The transfer of the material and mechanical properties between processes ensured an accurate prediction of shape distortions, weld bead size, and residual stresses.

Pérez Caro et al. (Ref. 176) conducted an integrated manufacturing process modeling to predict the final shape of a strip geometry extracted from a double-curved component manufactured from Alloy 718. The coupling of different manufacturing analyses, including cold forming, trimming, result mapping, welding, cooling, and springback, was achieved using LS-DYNA simulation software. Encouraging agreement was found between the model predictions and the results of forming and welding tests. The findings underscored the importance of including the material history and accurate process conditions along the manufacturing chain to the prediction accuracy of shape distortions.

\section{ICME Weld Modeling}

Traditionally, engineering practices have not accounted for residual stress fields and material changes after welding in structural design calculations. A large safety factor was given during structure design to account for the uncertainties. This design approach increases structure weight, reduces fuel efficiency, and limits structure performance. An ICME approach was proposed in which weld residual stress is predicted by a thermal-mechanical model, a microstructure model, and a property model (Ref. 177). Yang et al. (Ref. 178) applied this ICME modeling approach to optimize the design of welded structures in which weld residual stress was included as initial conditions before loading analysis. This ICME approach was also used to optimize welding processes to minimize distortion and ther- 
mal plate forming process to obtain an optimal forming path plan (Ref. 179). David et al. (Ref. 180) reviewed the progress in process modeling, microstructure, properties, and process control and automation, and the importance of integrated computational welding engineering (ICWE).

\section{Prospect for Future Research}

\section{Automatic Weld Mesh Generation}

Automatic mesh can be generated from a computer-aided design model for general structural analysis. But it is very limited in creating a weld mesh because fine mesh is needed in the weld area and coarse mesh is needed in the areas away from the weld to increase computational speed. It is time consuming to create a weld mesh for a large welded structure such as shipbuilding structures.

\section{Material Data for Weld Modeling}

Weld modeling requires temperature-dependent thermalphysical and mechanical material data up to material melting temperature. It is difficult to obtain the required material data from public literatures. There is a need to develop a comprehensive database for welding simulation.

\section{Commercial CFD Software to Predict Weld Bead Shape}

A welding experiment has to be conducted before an analysis to determine the heat-source model parameters for a thermal analysis. Because CFD can predict the weld bead shape, it would be useful to develop a commercial CFD software to predict weld bead shape.

\section{Fast Computational Solver for Welding Simulation}

Thermo-mechanical-metallurgical analysis is the most accurate method for predicting weld residual stress and distortion. But it could take weeks to analyze a large welded structure. Although fast computation solvers for welding have been developed in recent years, more studies are needed to further increase computational speed.

\section{Welding Cloud Computation}

To allow industry engineers to access weld modeling technologies, there is a need to develop a 3D welding cloud computation tool. This tool should be applicable to a production structure to predict temperature, microstructure, hardness, weld residual stress, and distortion. An engineer can access this tool from a production environment where the internet is available.

\section{Integrated Weld Model}

Individual models, including a CFD model, a grain growing model in a weld pool, a thermal model, a mechanical model, and a property model, have been developed by numerical experts in universities, research institutes, and national labs. Until now, there was little research to integrate all these models together for a true welding simulation.

\section{Integrated Manufacturing Process Simulation}

Integrated manufacturing process simulation is critical for new product design. If a new product can be built and evaluated in a virtual environment, it will result in huge savings for a company. This method can be used to optimize a product before a prototype is built.

\section{Conclusion}

Residual stresses and distortion existing in the welds can significantly impair the performance and reliability of welded structures. In the past two decades, there have been many significant and exciting developments in the prediction of weld residual stress and distortion. This paper reviewed the recent advances of numerical prediction methods. The review focused on the modeling theory and application in understanding weld residual stress and distortion. Two kinds of prediction methods were discussed: the thermo-mechanical-metallurgical method and simplified analysis methods.

The thermo-mechanical-metallurgical method is the most accurate method with major physics involved in the welding process including heat transfer, filler metal deposition, material melting, strain hardening, phase transformation, and large deformation. Heat source models were presented for commonly used welding processes. Experimental approach and CFD approach were discussed to obtain the parameters for heat source models. Model application examples were given to demonstrate the numerical method to solve industrial problems. However, the thermo-mechanical-metallurgical method could take weeks to run for a large welded structure in a current high-performance computer. Fast computational software and hardware are needed for full use in industries.

Simplified analysis methods were developed to shorten computational time. The methods include 2D modeling, lumping weld passes, combined 3D solid and shell elements, adaptive mesh technique, dual mesh method, iterative substructure method, instantaneous thermo-elastic-plastic method, prescribed temperature approach, inherent strain method, and local-to-global method. A combination of these methods could further reduce computational time. Among these methods, the inherent strain method is the most successfully and widely used, especially for large welded structures. Based on the inherent strain theory, other methods such as inherent deformation, average plastic strain, and equivalent load were developed for easily applying the inherent strain on a structure to predict distortion with an elastic analysis. The local-to-global method has become standard for applying the inherent strain method to predict residual stress and distortion. Some researchers reported that the inherent strain method under- or overpredicted weld distortion. This error is induced by the methods to obtain and apply the inherent strain in a FE model. If the inherent strain can be obtained and applied correctly, the inherent method can be an accurate analysis method.

FSW modeling methods were discussed separately in this paper because they involved physical couplings between ma- 
terial flow, heat transfer, and mechanics in the stirring zone around the pin. A transient thermal-elastic-plastic analysis method was introduced for residual stress and distortion prediction. Heat generated from friction and plasticity was modeled using a heat source model which includes a FSW tool, applied force, and rotation speed. This analysis method allows parametric study to optimize the FSW process to control residual stress and distortion. A simplified analysis method based on the inherent strain method was also introduced for predicting distortion in large structures.

Three buckling distortion analysis methods were discussed, which include a thermo-elastic-plastic method considering initial imperfection, an inherent deformation method, and an eigenvalue analysis method. Without including initial imperfection, FE models may be not able to predict the right deformation shape. Large deformation (nonlinear geometry) must be specified during distortion analysis using the shell-element model. The inherent deformation method is useful for buckling distortion prediction induced by fusion welding and FSW. The eigenvalue analysis, including welding residual stress, is a new analysis method that determines if a structure will buckle during welding and if a mitigation technique such as transient thermal tension can reduce the buckling propensity.

Welding cloud computation is a great tool to allow an engineer to apply modeling technology in industry to optimize welding processes, mitigate weld residual stress and distortion, and make smart decisions based on numerical model results before welding. Unfortunately, this tool is very limited now and needs to be upgraded to 3D models for real-world welded structures.

The integrated manufacturing process and ICME weld modeling are needed for virtual fabrication in developing new products. Limited studies have been conducted to explore this field. More developments are needed to evaluate a concept of new products in a virtual environment.

\section{References}

1. Gannon, L., Liu, Y., Pegg, N., and Smith, M. J. 2013. Effect of three-dimensional welding-induced residual stress and distortion fields on strength and behavior of flat-bar stiffened panels. Ships and Offshore Structures 8(5): 565-578.

2. Paik, J. K., and Sohn, J. M. 2012. Effects of welding residual stresses on high tensile steel plate ultimate strength: Nonlinear finite element method investigations. Journal of Offshore Mechanics and Arctic Engineering 134(2). DOI: 10.1115/OMAE2009-79297

3. McClung, R. C. 2007. A literature survey on the stability and significance of residual stresses during fatigue. Fatigue and Fracture of Engineering Materials and Structures 30(3): 173-205.

4. Brust, F. W., Dodds, R. H., Hobbs, J., Stoltz, B., and Wells, D. 2019. Weld residual stress and fracture behavior of NASA layered pressure vessels. Proceedings of the ASME 2019 Pressure Vessels \& Piping Conference, PVP2019-94021, July 14-19, San Antonio, Tex.

5. Dong, P., and Brust, F. W. 2000. Welding residual stresses and effects on fracture in pressure vessel and piping components: A millennium review and beyond. J. Pressure Vessel Technology 122(3): 329-338.

6. Dong, P. 2005. Residual stresses and distortions in welded structures: A perspective for engineering applications. Science and Technology of Welding and Joining 10(4): 389-398.

7. Dong, P., Song, S., and Zhang, J. 2014. Analysis of residual stress relief mechanisms in post-weld heat treatment. International
Journal of Pressure Vessels and Piping 122: 6-14

8. Peric, M., Garašic, I., Nižetic, S., and Dedic-Jandrek, H. 2018. Numerical analysis of longitudinal residual stresses and deflections in a T-joint welded structure using a local preheating technique.

Energies 11: 3487. DOI: 10.3390/ en 11123487

9. Cozzolino, L. D., Coules, E., Colegrove, A. P., and Wen, S. 2017. Investigation of post-weld rolling methods to reduce residual stress and distortion. J. Mater. Process. Tech. 247: 243-256.

10. Huang, T. D., Dong, P., Decan, L., Harwig, D., and Kumar, R. 2004. Fabrication and engineering technology for lightweight ship structures, Part 1: Distortions and residual stresses in panel fabrication. Journal of Ship Production 20(1): 43-59.

11. Feng, Z. 2005. Processes and Mechanisms of Welding Residual Stress and Distortion. Woodhead Publishing.

12. Michaleris, P. 2011. Minimization of Welding Distortion and Buckling. Modelling and Implementation. Woodhead Publishing.

13. Ni, J., Zhuang, X., and Wahab, M. A. 2020. Review on the prediction of residual stress in welded steel components. Computers, Materials \& Continua 62(2): 495-523.

14. Dong, P., Song, S., and Pei, X. 2016. An IIW residual stress profile estimation scheme for girth welds in pressure vessel and piping components. Weld World 60(2): 283-298.

15. Song, S. P., Dong, P., and Pei, X. 2015. A full-field residual stress estimation scheme for fitness-for-service assessment of pipe girth welds: Part I - Identification of key parameters. International Journal of Pressure Vessels and Piping 126(5): 8-70.

16. Mura, T. 2012. Micromechanics of Defects in Solids. Springer Science \& Business Media.

17. Brust, F. W., Hill, M. R., and Yang, Y. P. 2018. Residual stress and distortion. Welding Handbook $10^{\text {th }}$ Edition, Vol. 1. Chapter 7. Miami, Fla.: American Welding Society.

18. Prakash, B., Bhardwaj, M. Y., and Bansal, V. 2017. Review on finite element analysis for estimation of residual stresses in welded structures. Materials Today: Proceedings 4(9): 10230-10234.

19. Rong, Y., Xu, J., Huang, Y., and Zhang, G. 2018. Review on finite element analysis of welding deformation and residual stress. Science and Technology of Welding and Joining 23(3): 198-208.

20. Arora, H., Singh, R., and Brar, G. S. 2019. Thermal and structural modelling of arc welding processes: A literature review. Measurement and Control 52(7-8).

21. Ueda, Y., Murakawa, H., and Ma, N. 2012. Welding Deformation and Residual Stress Prevention. ISBN 978-0-12-394804-5. Elsevier Inc.

22. Coules, H. E. 2013. Contemporary approaches to reducing weld induced residual stress. Materials Science and Technology 29(1): 4-18.

23. Marques, E. S. V., Francisco, J. G. S., and Pereira, A. B. 2020. Comparison of finite element methods in fusion welding processes - A review. Metals 10(1): 75. DOI: 0.3390/met10010075

24. Goldak, J. A., and Akhlaghi, M. 2005. Computational Welding Mechanics. Springer.

25. Yang, Y. P., Brust, F. W., Fzelio, A., and McPherson, N. 2004. Weld modeling of thin structures with VFT software. ASME Pressure Vessels and Piping Conference, San Diego, Calif. July 25-29.

26. Long, H., Gery, D., Carlier, A., and Maropoulos, P. G. 2009. Prediction of welding distortion in butt joint of thin plates. Mater. Des. 30(10): 4126-4135.

27. Teng, T. L., Fung, C. P., Chang, P. H., and Yang, W. C. 2001. Analysis of residual stresses and distortions in T-joint fillet welds. Int. J. Press. Vessel Pip. 78(8): 523-538.

28. Schenk, T., Richardson, I. M., Kraska, M., and Ohnimus, S. 2009. Modeling buckling distortion of DP600 overlap joints due to gas metal arc welding and the influence of the mesh density. Comput. Mater. Sci. 46(4): 977-986.

29. Bhatti, A. A., Barsoum, Z., and Khurshid, M. 2014. Development of a finite element simulation framework for the prediction of residual stresses in large welded structures. Comput. Struct. 133: 1-11.

30. Chen, B. Q., and Soares, G. C. 2016. Numerical and experi- 
mental investigation on the weld-induced deformation and residual stress in stiffened plates with brackets. The International Journal of Advanced Manufacturing Technology 86: 2723-2733.

31. Okano, S., Tsuji, H., Ihara, R., and Mochizuki, M. 2018. Coupling computation between weld mechanics and arc plasma process for residual stress analysis. Materials Performance and Characterization 7(4): 559-573.

32. Yang, Y. P., Brust, F. W., and Cao, Z. 2003. Virtual fabrication technology weld modeling tool and its applications in distortion predictions. ASME Pressure Vessels and Piping Conference, Cleveland, Ohio

33. Venkatkuma, D., and Ravindran, D. 2016. 3D finite element simulation of temperature distribution, residual stress and distortion on 304 stainless steel plates using GTA welding. Journal of $\mathrm{Me}$ chanical Science and Technology 30: 67-76.

34. Joshi, S., Hildebrand, J., Aloraier, A. S., and Rabczuk, T. 2013. Characterization of material properties and heat source parameters in welding simulation of two overlapping beads on a substrate plate. Computational Materials Science 69: 559-565.

35. Wu, C. S., Wang, H. G., and Zhang, Y. M. 2006. A new heat source model for keyhole plasma arc welding in FEM analysis of the temperature profile. Welding Journal 85(12): 28-s to 291-s.

36. Kik, T., and Gorka, J. 2019. Numerical simulations of laser and hybrid S700MC T-joint welding. Materials (Basel) 12(3): 516. DOI: 10.3390/ma12030516

37. Sun, G. F., Wang, Z. D., Lu, Y., Zhou, R., Ni, Z. H., Gu, X., and Wang, Z. G. 2018. Numerical and experimental investigation of thermal field and residual stress in laser-MIG hybrid welded NV E690 steel plates. Journal of Manufacturing Processes 34A: 106-120.

38. Ma, N., Li, L., Huang, H., Chang, S., and Murakawa, H. 2015. Residual stresses in laser-arc hybrid welded butt-joint with different energy ratios. J. Mater. Process. Technol. 220: 36-45.

39. Ahmad, A. S., Wu, Y., Gong, H., and Nie, L. 2019. Finite element prediction of residual stress and deformation induced by double-pass TIG welding of Al 2219 plate. Materials 12: 2251.

40. Zhang, W. J., Liu, Y. K., and Zhang, Y. M. 2012. Real-time measurement of three dimensional weld pool surface in GTAW. Chapter 14 of Welding Processes. Ed. R. Kovacevic. eBook ISBN: 978-95351-0854-2. DOI: 10.5772/53753

41. Sharma, A., Chaudhary, A. K., Arora, N., and Mishra, B. K. 2009. Estimation of heat source model parameters for twin-wire submerged arc welding. Int. J. Adv. Manuf. Technol. 45: 1096-1103.

42. Yadaiah, N., and Bag, S. 2012. Effect of heat source parameters in thermal and mechanical analysis of linear GTA welding process. The Iron and Steel Institute of Japan 52: 2069-2075.

43. Sun, J., Klassen, J., and Nitschke-Pagel, T. et al. 2018. Effects of heat source geometric parameters and arc efficiency on welding temperature field, residual stress, and distortion in thin-plate fullpenetration welds. The International Journal of Advanced Manufacturing Technology 99: 497-515.

44. Li, P., Fan, Y., Zhang, C., Zhu, Z., Tian, W., and Liu, A. 2018. Research on heat source model and weld profile for fiber laser welding of A304 stainless steel thin sheet. Advances in Materials Science and Engineering 5895027. DOI: 10.1155/2018/5895027

45. Yadaiah, N., and Bag, S. 2014. Development of egg-configuration heat source model in numerical simulation of autogenous fusion welding process. Int. J. Therm. Sci. 86: 125-138.

46. Yue, J., Dong, X., Guo, R., Liu, W., and Li, L. 2019. Numerical simulation of equivalent heat source temperature field of asymmetrical fillet root welds. Int. J. Heat Mass Tran. 130: 42-49.

47. Nart, E., and Celik, Y. 2013. A practical approach for simulating submerged arc welding process using FE method. J. Constr. Steel Res. 84: 62-71.

48. Arrizubieta, J. I., Lamikiz, A., Klocke, F., Martínez, S., Arntz, K., and Ukar, E. 2017. Evaluation of the relevance of melt pool dynamics in laser material deposition process modeling. Int. J. Heat Mass Tran. 115: 80-91.

49. Zhang, W., Roy, G., Elmer, J. W., and DebRoy, T. 2003. Modeling of heat transfer and fluid flow during gas tungsten arc spot weld- ing of low carbon steel. Journal of Applied Physics 93: 3022-3033.

50. Cao, Z., Yang, Z., and Chen, X. 2004. Three-dimensional simulation of transient GMA weld pool with free surface. Welding Journal 83(6): 169-176.

51. Bag, S., Kiran, D. V., Syed, A. A., and De, A. 2012. Efficient estimation of volumetric heat source in fusion welding process simulation. Welding in the World 56: 88-97.

52. Podder, D., Mandal, N. R., and Das, S. 2014. Heat source modeling and analysis of submerged arc welding. Welding Journal 93(5): 183-192.

53. Cheon, J., Kiran, D. V., and Na, S. J. 2016. Thermal metallurgical analysis of GMA welded AH36 steel using CFD-FEM framework. Materials \& Design 91: 230-241.

54. Turner, R. P., Panwisawas, C., Sovani, Y. et al. 2016. An integrated modeling approach for predicting process maps of residual stress and distortion in a laser weld: A combined CFD-FE methodology. Metall. and Materi. Trans. B 47: 2954-2962.

55. Anthony, B. M., Nguyen, V., Feng, Y., David, G. T., and Dayalan, G. 2017. A desktop computer model of the arc, weld pool and workpiece in metal inert gas welding. Applied Mathematical Modeling 44: 91-106.

56. Yang, Y. P., Castner, H., and Kapustka, N. 2011. Development of distortion modeling methods for large welded structures. Transactions - Society of Naval Architects and Marine Engineers 119: 645-653.

57. Wang, C., Kim, Y. R., and Kim, J. W. 2014. Comparison of FE models to predict the welding distortion in T-joint gas metal arc welding process. International Journal of Precision Engineering and Manufacturing 15(8): 1631-1637. DOI: 10.1007/s12541-014-0513-8

58. Fanous, F. Z. I., Maher, Y. A., and Wifi, S. A. 2003. 3D finite element modeling of the welding process using element birth and element movement techniques. Transactions ASME Journal of Pressure Vessel Technology 125: 144-150.

59. Biswas, P., and Mandal, N. R. 2010. Thermomechanical finite element analysis and experimental investigation of single-pass singlesided submerged arc welding of C-Mn steel plates. Proceedings of the Institution of Mechanical Engineers, Part B: Journal Engineering Manufacture 224(B4): 627-639.

60. Lindgren, L.-E., and Hedblom, E. 2001. Modelling of addition of filler material in large deformation analysis of multipass welding. Communications in Numerical Methods in Engineering 17(9): 647-657.

61. Peric, M., Tonkovic, Z., Karšaj, I., and Stamenkovic, D. 2018. A simplified engineering method for a T-joint welding simulation. Therm. Sci. 22: 867-873.

62. Peric, M., Nižetic, S., Garašic, I., Gubeljak, N., Vuherer, T., and Tonkovic, Z. 2020. Numerical calculation and experimental measurement of temperatures and welding residual stresses in a thick-walled T-joint structure. Journal of Thermal Analysis and Calorimetry. DOI: 10.1007/s10973-019-09231-3

63. Peric, M., Garašic, I., Tonkovic, Z., Vuherer, T., Nižetic, S., and Dedic-Jandrek, H. 2019. Numerical prediction and experimental validation of temperature and residual stress distributions in buried-arc welded thick plates. Int. J. Energy Res. 43(8): 3590-3600.

64. Lundbäck, A. 2010. Modeling and simulation of welding and metal deposition. PhD diss., Luleå University of Technology.

65. Yang, Y. P., and Babu, S. S. 2010. An integrated model to simulate laser cladding manufacturing process for engine repair applications. Welding in the World 54(9-10): r298-r307.

66. Huang, T. D., Rucker, H. J., and Yang, Y. P. 2019. An ICME modeling application for the optimization of tie-down weld sequence in ship production. Journal of Ship Production and Design 35(2): 190-197.

67. Yang, Y. P., Jamshidinia, M., Boulware, P., and Kelly, S. 2017. Prediction of microstructure, residual stress, and deformation in laser powder bed fusion process. Computational Mechanics 61(5): 599-615.

68. Lindgren, L. E., Lundbäck, A., and Malmelöv, A. 2019. Thermal stresses and computational welding mechanics. Journal of Thermal Stresses 42(1): 107-121.

69. Armentani, E., Esposito, R., and Sepe, R. 2007. The effect of 
thermal properties and weld efficiency on residual stresses in welding. Journal of Achievements in Materials and Manufacturing Engineering 20: 319-322.

70. Zhu, X. K., and Chao, Y. J. 2002. Effects of temperaturedependent material properties on welding simulation. Computers \& Structures 80(11): 967-976.

71. Schwenk, C., and Rethmeier, M. 2011. Material properties for welding simulation - Measurement, analysis, and exemplary data. Welding Journal 90(11): 220-s to 22-s.

72. Kaars, J., Mayr, P., and Koppe, K. 2018. Determiningmaterial data for welding simulation of press hardened steel. Metals 8: 740. DOI: $10.3390 /$ met 8100740

73. Bhatti, A. A., Barsoum, Z., Murakawa, H., and Barsoum, I. 2015. Influence of thermo-mechanical material properties of different steel grades on welding residual stresses and angular distortion. Mater. Des. 65: 878-889.

74. Bechetti, D. H., Semple, J. K., Zhang, W., and Fisher, C. R. 2019. Temperature-Dependent Material Property Databases for Marine Steels - Part 1: DH36. NSWCCD-61-TR-2019/03. Naval Surface Warfare Center Carderock Division, West Bethesda, Md. 20817-5700.

75. Yang, Y. P., Dong, P., and Zhang, J. 2000. A hot-cracking mitigation technique for welding high-strength aluminum alloy. Welding Journal 79(1): 9-s to 17-s.

76. Huang, H., Tsutsumi, S., Wang, J. C., Li, L., and Murakawa, H. 2017. High performance computation of residual stress and distortion in laser welded 301L stainless sheets. Finite Elements in Analysis and Design 135(1): 1-10.

77. Mullins, J., and Gunnars, J. 2009. Effect of hardening model on the weld residual stress field in pipe girth welds. IASMiRT. lib.ncsu.edu/resolver/1840.20/23582

78. Xiong, Q., Smith, M. C., Muranskyb, O., and Mathewd, J. 2019. Validated prediction of weld residual stresses in austenitic steel pipe girth welds before and after thermal ageing, Part 2: Modelling and validation. International Journal of Pressure Vessels and Piping 172: 430-448.

79. Deng, D., and Murakawa, H. 2013. Influence of transformation induced plasticity on simulated results of welding residual stress in low temperature transformation steel. Comput. Mater. Sci. 78: 55-62.

80. Payares-Asprino, M. C., Katsumoto, H., and Liu, S. 2008. Effect of martensite start and finish temperature on residual stress development in structural steel welds. Welding Journal 87(11): 279-s to 289-s.

81. Deng, D., Zhang, Y., Li, S., and Tong, Y. 2016. Influence of solid-state phase transformation on residual stress in P92 steel welded joint. Acta Metall. Sin. 52: 394-402.

82. Yaghi, A., Hyde, T. H., Becker, A. A., and Sun, W. 2018. Finite element simulation of welding and residual stresses in a P91 steel pipe incorporating solid-state phase transformation and postweld heat treatment. J. Strain Anal. Eng. Des. Prof. 43(5): 275-293.

83. Deng, D., and Murakawa, H. 2006. Prediction of welding residual stress in multi-pass butt-welded modified $9 \mathrm{Cr}$-1Mo steel pipe considering phase transformation effects. Comput. Mater. Sci. 37: 209-219.

84. Xu, G., Guo, Q., Hu, Q., et al. 2019. Numerical and experimental analysis of dissimilar repair welding residual stress in P91 steel considering solid-state phase transformation. Journal of Materials Engineering and Performance 28: 5734-5748.

85. Chen, W., Xu, L., Zhao, L., Han, Y., Jing, H., Zhang, Y., and Li, Y. 2020. Thermo-mechanical-metallurgical modeling and validation for ferritic steel weldments. Journal of Constructional Steel Research 166: 105948. DOI: 10.1016/j.jcsr.2020.105948

86. Xia, J., and Jin, H. 2018. Numerical modeling of coupling thermal-metallurgical transformation phenomena of structural steel in the welding process. Advances in Engineering Software 115: 66-74.

87. Yang, Y. P., Brust, F. W., Zhang, J., Cao, Z., Dong, Y., Nanjun- dan, A., Varol, I., and Jutla, T. 2000. Weld modeling procedures development of lap joint. International Conference on Computer Engineering and Science, Los Angeles, Calif., August 21-25.

88. Deng, D. 2009. FEM prediction of welding residual stress and distortion in carbon steel considering phase transformation effects. Materials \& Design 30(2): 359-366.

89. Zhou, H., Zhang, Q., Yi, B., and Wang, J. 2020. Hardness prediction based on microstructure evolution and residual stress evaluation during high tensile thick plate butt welding. International Journal of Naval Architecture and Ocean Engineering 12: 146-156.

90. Yang, Y. P., and Dong, P. 2012. Buckling distortions and mitigation techniques for thin-section structures. Journal of Materials Engineering and Performance 21(2): 153-160.

91. Brust, F. W., Scott, P. M., and Yang, Y. P. 2002. Weld residual stresses and cracking in bimetallic hot leg nuclear weld. ASME Pressure Vessels and Piping Conference, Vancouver, British Columbia, Canada. August 4-8.

92. Yang, Y. P., Babu, S., Vaze, S., Kikel, J., and Dewees, D. 2008. Crack mitigation during buttering and cladding of a low alloy steel pipe. Proceedings of the $8^{\text {th }}$ International Conference on Trends in Welding Research, Pine Mountain, Ga., June 2-6.

93. Hashemzadeh, M., Chen, B.-C., and Soares, C. G. 2018. Evaluation of multi-pass welding-induced residual stress using numerical and experimental approaches. Ships and Offshore Structures 13(8): 847-856.

94. Lundbäck, A. 2003. Finite element modelling and simulation of welding of aerospace components. PhD diss., Luleå University of Technology.

95. Ikushima, K., Itoh, S., and Shibahara, M. 2015. Development of idealized explicit FEM using GPU parallelization and its application to large-scale analysis of residual stress of multi-pass welded pipe joint. Weld World 59: 589-595.

96. Ma, N. 2016. An accelerated explicit method with GPU paralle computing for thermal stress and welding deformation of large structure models. Int. J. Adv. Manuf. Technol. 87: 2195-2211.

97. Dong, P., and Hong, J. K. 2003. Recommendations on residual stress estimate for fitness-for-service assessment. WRC Bulletin 476.

98. Boring, M. A., and Yang, Y. P. 2008. Amine tower repair using temper bead welding. Australasian Welding Journal 53: 20-22.

99. Zang, W., Gunnars, J., Dong, P., and Hong, J. K. 2009. Improvement and Validation of Weld Residual Stress Modelling Procedure (SSM-2009-15). Sweden. stralsakerhetsmyndigheten.se/In-English/Publ

100. Zhu, J., Khurshid, M., and Barsoum, Z. 2019. Assessment of computational weld mechanics concepts for estimation of residual stresses in welded box structures. Procedia Structural Integrity 17: 704-711.

101. Park, J. U., An, G., and Kim, S. 2017. The effect of weldingpass grouping on the prediction accuracy of residual stress in multipass butt welding. Mathematical Problems in Engineering 1: 1-13.

102. Kim, D. 2003. Welding simulation of ship structures using coupled shell and solid volume finite elements. PhD diss., Lehigh University.

103. Peric, M., Seleš, K., Tonkovic, Z., and Lovrenic-Jugovic, M. 2019. Numerical simulation of welding distortions in large struc tures with a simplified engineering approach. Open Physics 17: 1. DOI: 10.1515/phys-2019-0076

104. Deng, D., Murakawa, H., and Liang, W. 2008. Prediction of welding distortion in a curved plate structure by means of elastic finite element method. J. Mater. Process. Tech. 203: 252-266.

105. Chen, Z., Yu, Q., Luo, Y., and Shenoi, R. A. 2019. Comparative study of welding deformation of a stiffened panel under various welding procedures. P. I. Mech. Eng. B-J. Eng. 233: 182-191.

106. Runnemalm, H., and Hyun, S. 2000. Three-dimensional welding analysis using an adaptive mesh scheme. Comput. Methods Appl. Mech. Eng. 189(2): 515-523.

107. Hamide, M., Elisabeth, M., and Michel, B. 2008. Adaptive mesh technique for thermal-metallurgical numerical simulation of 
arc welding processes. Int. J. Numer. Methods Eng. 73(5): 624-641.

108. Huang, H., Ma, N., Murakawa, H., and Feng, Z. 2019. A dualmesh method for efficient thermal stress analysis of large-scale welded structures. Int. J. Adv. Manuf. Tech. 103: 769-780.

109. Maekawa, A., Kawahara, A., Serizawa, H., and Murakawa, H. 2015. Fast three-dimensional multipass welding simulation using an iterative substructure method. J. Mater. Process. Technol. 215: 30-41.

110. Huang, H., Ma, N., Hashimoto, T., and Murakawa, H. 2015. Welding deformation and residual stresses in arc welded lap joints by modified iterative analysis. Science and Technology of Welding and Joining 20(7): 571-577.

111. Maekawa, A., Kawahara, A., Serizawa, H., and Murakawa, H. 2016. Prediction of weld residual stress in a pressurized water reactor pressurizer surge nozzle. ASME J. Pressure Vessel Technol. 138(2): 021401. DOI: 10.1115/1.4031376

112. Barsouma, Z., Bhatti, A. A., and Balawi, S. 2015. Computational weld mechanics - Towards a simplified and cost effective approach for large welded structures. Procedia Engineering 114: 62-69.

113. Yang, Y. P., Brust, F. W., and Kennedy, J. C. 2002. Lump-pass welding simulation technology development for shipbuilding applications. ASME Pressure Vessels and Piping Conference, Vancouver, British Columbia, Canada, Aug. 4-8.

114. Pu, X., Zhang, C., Li, S., and Deng, D. 2017. Simulating welding residual stress and deformation in a multi-pass butt-welded joint considering balance between computing time and prediction accuracy. Int. J. Adv. Manuf. Technol. 93: 2215-2226.

115. Seleš, K., Peric, M., and Tonkovic, Z. 2018. Numerical simulation of a welding process using a prescribed temperature approach. $J$. Constr. Steel Res. 14: 49-57.

116. Sun, Y., Li, D., Zhang, Z., Yan, D., and Shi, Q. 2011. Establishment of traveling temperature function method and its application on welding distortion prediction of cylindrical and conical aluminum alloy structures. Acta Metallurgica Sinica - Chinese Edition 47: 1403-1407. DOI: 10.3724/SP.J.1037.2011.00320

117. Sun, Y., Shi, Q., Sun, K., Chen, G., and Meng, L. 2012. Process optimization to control welding distortion of high speed train roof by high efficiency numerical simulation. Proceeding of the $9^{\text {th }}$ International Conference on Trends in Welding Research, Chicago, Ill. June 4-8.

118. Khurram, A., and Shehzad, K. F. E. 2012. Simulation of welding distortion and residual stresses in butt joint using inherent strain. International Journal of Applied Physics and Mathematics 2(6): 405-408.

119. Wang, J., Yuan, H., Ma, N., and Murakawa, H. 2016. Recent research on welding distortion prediction in thin plate fabrication by means of elastic FE computation. Marine Structures 47: 42-59.

120. Zhou, H., and Wang, J. 2018. Accurate FE computation for out-of-plane welding distortion prediction of fillet welding with considering self-constraint. Journal of Ship Production and Design 35. DOI: 10.5957/JSPD.03180006

121. Peric, M., Seleš, K., Tonkovic, Z., and Lovrenic-Jugovic, M. 2019. Numerical simulation of welding distortions in large structures with a simplified engineering approach. Open Physics 17(1). DOI: 10.1515/phys-2019-0076

122. Jung, G. H., and Tsai, C. L. 2004. Plasticity-based distortion analysis for fillet welded thin-plate T-joints. Welding Journal 83(6): 177 -s to 187 -s.

123. Lu, Y., Zhu, S., Zhao, Z., Chen, T., and Zeng, J. 2020. Numerical simulation of residual stresses in aluminum alloy welded joints. Journal of Manufacturing Processes 50: 380-393.

124. Deng, D., Murakawa, H., and Liang, W. 2007. Numerical simulation of welding distortion in large structures. Computer Methods in Applied Mechanics and Engineering: 196 (45-48): 4613-4627.

125. Deng, D., Murakawa, H., and Shibahara, M. 2010. Investigations on welding distortion in an asymmetrical curved block by means of numerical simulation technology and experimental method. Comp. Mater. Sci. 48: 187-194.

126. Duan, Y. G., Vincent, Y., Boitout, F., Leblond, J. B., and Bergheau, J. M. 2007. Prediction of welding residual distortions of large structures using a local/global approach. J. Mech. Sci. Technol. 21(10): 1700-1706.

127. Wang, J., Ma, N., Murakawa, H., Teng, B., and Yuan, S. 2011. Prediction and measurement of welding distortion of a spherical structure assembled from multi thin plates. Materials \& Design 32 (10): 4728-4737.

128. Wang, R., Zhang, J., Serizawa, H., and Murakawa, H. 2009. Study of welding inherent deformations in thin plates based on finite element analysis using interactive substructure method. Mater. Des. 30(9): 3474-3481.

129. Tian, L., and Luo, Y. 2020. A study on the prediction of inherent deformation in fillet-welded joint using support vector machine and genetic optimization algorithm. Journal of Intelligent Manufacturing 31(3): 575-596.

130. Tian, L., and Luo, Y. 2019. A comparison study of BPN and SVM prediction models for inherent deformations of T-welded joints. Mechanics of Advanced Materials and Structures. DOI: 10.1080/ 15376494.2019.1567881

131. Biswas, P., Mandal, N. R., and Das, S. 2011. Prediction of welding deformations of large stiffened panels using average plastic strain method. Science and Technology of Welding and Joining 16(3): 227-231.

132. Khurram, A., and Shehzad, K. 2012. FE simulation of welding distortion and residual stresses in butt joint using inherent strain. International Journal of Applied Physics and Mathematics 2(6): 405.

133. Suman, S., Sridhar, P., Biswas, P., and Das, D. 2019. Prediction of welding-induced distortions in large weld structure through improved equivalent load method based on average plastic strains. Welding in the World 64. DOI: 10.1007/s40194-019-00805-1

134. Barsoum, Z., Ghanadi, M., and Balawi, S. 2015. Managing welding induced distortion - comparison of different computational approaches. Procedia Engineering 114: 70-77.

135. Biswas, P., and Mandal, N. R. 2009. A comparative study of three different approaches of FE analysis for prediction of welding distortion of orthogonally stiffened plate panels. J. Ship Prod. 25(4): 1-7.

136. Deng, D., Murakawa, H., and Liang, W. 2007. Numerical simulation of welding distortion in large structures. Comput. Methods Appl. Mech. Eng. 196(45-48): 4613-4627.

137. Murakawa, H., Deng, D., Ma, N., and Wang, J. 2012. Applications of inherent strain and interface element to simulation of welding deformation in thin plate structures. Comput. Mater. Sci. 51(1): 43-52.

138. Li, Y., Wang, K., Jin, Y., Xu, M., and Lu, H. 2015. Prediction of welding deformation in stiffened structure by introducing thermomechanical interface element. J. Mater. Process. Technol. 216: 440446.

139. Wang, J., Rashed, S., Murakawa, H., and Luo, Y. 2013. Numerical prediction and mitigation of out-of-plane welding distortion in ship panel structure by elastic FE analysis. Mar. Struct. 34: 135-155.

140. Souloumiac, B., Boitout, F., and Bergheau, J. M. 2002. A new local-global approach for the modelling of welded steel component distortions. Math. Model. Weld. Phenom 6: 573-590.

141. Yang, Y. P., and Athreya, B. P. 2012. A Local-to-Global Assembling Method to Predict Distortion. AWS Professional Program at the FABTECH Show, Las Vegas, Nev. youtube.com/watch?v=SvOG-dFPFg8

142. Jung, G., and Yang, Y. P. 2005. Prediction of welding distortion with Q-Weld. ABAQUS Annual User Conference, Lafayette, Ind., Sept. 27-28.

143. Tsirkas, S. A., Papanikos, P., Pericleous, K., Strusevich, N., Boitout, F., and Bergheau, J. M. 2003. Evaluation of distortions in laser welded shipbuilding parts using local-global finite element approach. Science and Technology of Welding \& Joining 8(2): 79-88.

144. Yang, Y. P., and Athreya, B. P. 2013. An improved plasticitybased distortion analysis method for large welded structures. Journal of Materials Engineering and Performance 22(5): 1233-1241.

145. Zhu, J., Khurshid, M., and Barsoum, Z. 2019. Accuracy of 
computational welding mechanics methods for estimation of angular distortion and residual stresses. Welding in the World 63: 1391-1405.

146. He, X., Gu, F., and Ball, A. 2014. A review of numerical analysis of friction stir welding. Prog. Mater. Sci. 65(10): 1-66.

147. Schmidt, H., Hattel, J., and Wert, J. 2004. An analytical model for the heat generation in friction stir welding. Model. Simul. Mater. Sci. Eng. 12: 143-157.

148. Xu, S., Deng, X., Reynolds, A. P., and Seidel, T. U. 2001. Finite element simulation of material flow in friction stir welding. Sci. Technol. Weld. Join. 6: 191-193.

149. Schmidt, H. N. B., Dickerson, T. L., and Hattel, J. H. 2006. Material flow in butt friction stir welds in AA2024-T3. Acta Mater. 54: 1199-1209.

150. Khandkar, M. Z. H., Khan, J. A., and Reynolds, A. P. 2003. Prediction of temperature distribution and thermal history during friction stir welding: Input torque based model. Sci. Technol. Weld. Join. 8: 165-174.

151. Nandan, R., Roy, G. G., and Lienert, T. J. 2006. Numerical modelling of 3D plastic flow and heat transfer during friction stir welding of stainless steel. Sci. Technol. Weld. Join. 11: 526-537.

152. Yang, Y. P. 2015. Developing friction stir welding process model for ICME application. Journal of Materials Engineering and Performance 24(1): 202-208.

153. Li, T., Shi, Q., and Li, H. K. 2007. Residual stresses simulation for friction stir welded joint. Science and Technology of Welding and Joining 12(8): 664-670.

154. Yan, D., Shi, Q., and Wu, A. 2009. Numerical analysis on the functions of stir tool's mechanical loads during friction stir welding. Acta Metallurgica Sinica 45: 994-999.

155. Khosa, S. U., Weinberger, T., and Enzinger, N. 2010. Thermomechanical investigations during friction stir spot welding (FSSW) of AA6082-T6. Weld World 54: R134-146.

156. Yan, D., Wu, A., Silvanus, J., and Shi, Q. 2011. Predicting residual distortion of aluminum alloy stiffened sheet after friction stir welding by numerical simulation. Materials and Design 32: 22842291.

157. Nie, L., Wu, Y. X., and Gong, H. 2020. Prediction of temperature and residual stress distributions in friction stir welding of aluminum alloy. Int. J. Adv. Manuf. Technol. 106: 3301-3310.

158. Costa, M. I., Leitão, C., and Rodrigues, D. M. 2019. Parametric study of friction stir welding induced distortion in thin aluminium alloy plates: A coupled numerical and experimental analysis. ThinWalled Struct. 134: 268-276.

159. Yu, H., Li, Y., Xu, X., and Zheng, B. 2020. Out-of-plane distortion prediction of large thin-walled structures induced by friction stir welding. Science and Technology of Welding and Joining 25(1): 45-55.

160. Jang, C. D., and Jang, Y. J. 2010. Welding deformation analysis of friction stir welded aluminum alloy structures using equivalent load method based on inherent strain. Proceedings of the International Offshore and Polar Engineering Conference Vol. 4: 290-297.

161. Dialami, N., Cervera, M., Chiumenti, M., and Agelet de Saracibar, C. 2017. Local-global strategy for the prediction of residual stresses in FSW processes. Int. J. Adv. Manuf. Technol. 88(9-12): 1-13.

162. Yang, Y. P., Brust, F. W., Dong, P., Zhang, J., and Cao, Z. 2000. Modeling procedure development of buckling distortion in thin plate welding. Proceedings of ASME PVP Conference: A Century of Progress in PVP Technology, Seattle, Wash.

163. Deng, D., and Murakawa, H. 2008. FEM prediction of buckling distortion induced by welding in thin plate panel structures. Comput. Mater. Sci. 43: 591-607.

164. Wang, J., Yi, B., and Zhou, H. 2018. Framework of computational approach based on inherent deformation for welding buckling investigation during fabrication of lightweight ship panel. Ocean Engineering 157: 202-210.

165. Wang, J., Ma, N., and Murakawa, H. 2015. An efficient FE computation for predicting welding induced buckling in production of ship panel structure. Mar. Struct. 41: 20-52.

166. Yang, Y. P., Dull, R., Conrardy, C., Porter, N., Dong, P., and
Huang, T. D. 2008. Transient thermal tensioning and numerical modeling of thin steel ship panel structures. Journal of Ship Production 24(1): 37-49.

167. Wang, J., Rashed, S., and Murakawa, H. 2014. Mechanism investigation of welding induced buckling using inherent deformation method. Thin-Walled Struct. 80(1): 103-119.

168. Yang, Y. P., Zhang, W., Gan, W., Khurana, S., Xu, J., and Babu, S. 2008. Online software tool for predicting weld residual stress and distortion. Proceedings of 2008 ASME Pressure Vessels and Piping Division Conference, PVP2008-61123, Vol. 6: 279-288, Chicago, Ill.

169. Yang, Y. P., Zhang, W., Bohr, J., and Kimchi, M. 2009. Development of online weld modeling tool for automotive applications. Proceedings of International Automotive Body Congress (IABC), November 4-5, 2009, Troy, Mich.

170. Zhang, W., and Yang, Y. P. 2009. Development and application of on-line weld modeling tool. Welding in the World 53(1/2): 67-75.

171. Shaxted, M., Yang, Y. P., and Mehrabadi, M. 2018. Welding cloud computational applications for digital manufacturing. The Conference on Advancing Analysis and Simulation in Engineering (CAASE18), Cleveland, Ohio. nafems.org/publications/resource_center/caase_jun_18_76/

172. Schill, M., and Odenberger, E. L. 2014. Simulation of residual deformation from a forming and welding process using LSDYNA. Proceedings of the $13^{\text {th }}$ International LS-DYNA User's Conference, Detroit, Mich.

173. Steffenburg-Nordenström, J., and Larsson, M. 2014. Simulation of the influence of forming on residual stresses and deformations after welding and heat treatment in alloy 718. Proceedings of the $11^{\text {th }}$ World Congress on Computational Mechanics: 1657-1666. Barcelona, Spain.

174. Huang, H., Yin, X., Feng, Z., and Ma, N. 2019. Finite element analysis and in-situ measurement of out-of-plane distortion in thin plate TIG welding. Materials 12: 141-158.

175. Bauer, A., Manurung, Y. H. P., Sprungk, J., Graf, M., Awiszus, B., and Prajadhiana, K. 2019. Investigation on forming-welding process chain for DC04 tube manufacturing using experiment and FEM simulation. Int. J. Adv. Manuf. Technology 102: 23992408.

176. Pérez Caro, L., Odenberger, E., Schill, M. et al. 2020. Prediction of shape distortions during forming and welding of a double-curved strip geometry in alloy 718. Int. J. Adv. Manuf Technology. DOI: 0.1007/s00170-020-05118-y

177. Gou, G., Yang, Y. P., and Chen, H. 2014. An ICME approach for optimizing thin welded structure design. Engineering 6(13): 936-947. DOI: 10.4236/eng.2014.613085

178. Yang, Y. P., and Gould, J. 2014. ICME application in designing welded structures. Thermal Process Modeling: Proceedings from the Fifth International Conference on Thermal Process Modeling and Computer Simulation: 209-216, ASM International.

179. Yang, Y. P., Kim, H., Mohr, W. C., Castner, H., Huang, T. D., and Fanguy, D. 2015. ICME applications in optimizing welding and thermal-forming processes. Proceedings of the $3^{\text {rd }}$ World Congress on Integrated Computational Materials Engineering (ICME), Wiley, ISBN 1119139511. Colorado Springs, Colo., May 31-June 4.

180. David, S. A., Chen, J., Gibson, B. T., and Feng, Z. 2017. Intelligent weld manufacturing: Role of integrated computational welding engineering. Transactions on Intelligent Welding Manufacturing. DOI: 10.1007/978-981-10-7043-3_1

YU-PING YANG (yupingyang@yahoo.com) was with the Edison Welding Institute, Columbus, Ohio, at the time this review was conducted. 